\title{
Detection of EBV, HBV, HCV, HIV-1, HTLV-I and -II, and SMRV in Human and Other Primate Cell Lines
}

\author{
Cord C. Uphoff, Sabine A. Denkmann, Klaus G. Steube, and Hans G. Drexler \\ Department of Human and Animal Cell Lines, German Collection of Microorganisms and Cell Cultures DSMZ, \\ Inhoffenstraße 7b; 38124 Braunschweig, Germany \\ Correspondence should be addressed to Cord C. Uphoff, cup@dsmz.de
}

Received 30 September 2009; Revised 21 January 2010; Accepted 10 February 2010

Academic Editor: Ellen Collisson

Copyright () 2010 Cord C. Uphoff et al. This is an open access article distributed under the Creative Commons Attribution License, which permits unrestricted use, distribution, and reproduction in any medium, provided the original work is properly cited.

\begin{abstract}
The high prevalence of contaminated cell cultures suggests that viral contaminations might be distributed among cultures. We investigated more than 460 primate cell lines for Epstein-Barr (EBV), hepatitis B (HBV), hepatitis C (HCV), human immunodeficiency virus type 1 (HIV-1), human T-cell leukemia/lymphoma virus I and II (HTLV-I/-II), and squirrel monkey retrovirus (SMRV) infections for risk assessment. None of the cell lines were infected with HCV, HIV-1, or HTLV-I/-II. However, one cell line displayed reverse transcriptase activity. Thirty-nine cell lines harbored EBV DNA sequences. Studies on the lytic phase of EBV revealed that five cell lines produce EBV particles and six further cell lines produced EBV upon stimulation. One cell line contained an integrated HBV genome fragment but showed no virus production. Six cell lines were SMRV-infected. Newly established cell lines should be tested for EBV infections to detect B-lymphoblastoid cell lines (B-LCL). B-LCLs established with EBV from cell line B95-8 should be tested for SMRV infections.
\end{abstract}

\section{Introduction}

Human primary cell cultures and cell lines have become fundamental tools for basic research in numerous life science faculties as well as for the production of bioactive reagents in biomedicine and biotechnology. They are already used for several decades and frozen cell cultures or blood and tissue samples obtained many years ago can be found in numerous laboratories. As known from experience in the transfusion and transplantation medicine, human cells can harbor a number of different human pathogens and conveyed a potential risk for the recipients to become infected before extensive screenings of the material were accomplished. In particular, human pathogenic viruses like human immunodeficiency virus type 1 (HIV-1), human Tcell leukemia/lymphoma virus type I and II (HTLV-I and -II), and hepatitis viruses, for example, hepatitis B virus (HBV) and hepatitis $\mathrm{C}$ virus ( $\mathrm{HCV})$, are found in human donor and patient material [1]. Cell lines were usually established from patient material which might similarly be infected with those viruses or perhaps with viruses linked to specific tumors, for example, human herpes virus type 8 (HHV-8) or novel types of papilloma viruses [2]. A considerable percentage of cell lines was established before viral contaminations had been routinely assayed or even before those viruses had been discovered. Additionally, the risk of emerging pathogens has to be kept under constant review [3].

Indeed, some cell lines are known to harbor human pathogenic viruses, among them the well-known and widely distributed HeLa cell line which contains the human papilloma virus integrated into its genome [4]. Besides the infection of the primary material which may be traced back to the donor, contaminations of cell cultures can also be introduced secondarily by laboratory personnel or from other infected cells when handled simultaneously. Such means of infection are much more likely, as similar problems were shown for mycoplasma contaminations (an incidence of ca. 25\% has been reported) and cross contaminations of cell cultures (ca. 15\%) [5]. This type of infection with transmissible viruses might be true for the contamination with squirrel monkey retrovirus (SMRV), which was detected in some human and 
animal cell lines; sequences of the virus were shown to be present in interferon- $\alpha$ preparations produced by the human Burkitt lymphoma cell line NAMALWA $[6,7]$.

Human and animal cells themselves represent no increased risk during routine cell culture. But an infection of the cells with human pathogenic viruses or bacteria increases the potential risk of a cell culture. Although the probability of the unintentional establishment of a cell line which is infected with a high-risk virus is extremely low, primary cells and cell cultures of unknown origin should be regarded as potentially harmful and are categorized as risk group 2, at least until the infection status of the donor or the cells is clearly determined. Whereas some viruses can be easily propagated in continuous cell lines (e.g., human retroviruses), propagation of other viruses depends on the microenvironment or maturation of the otherwise permissive cells. Additionally, some viruses exhibit a latent or cryptic infection cycle, during which no active viruses are produced (e.g., Epstein-Barr virus (EBV), proviruses of retroviruses). However, the latent status can be switched to the productive lytic cycle by certain inducers, or constantly low replication rates can be found [8].

In this report, we describe the use of polymerase chain reaction (PCR) assays, enzyme-linked immunosorbent assay (ELISA), Southern and Western blotting for the detection of latent and active forms of the human pathogenic viruses (EBV, HBV, HCV, HIV-1, HTLV-I and -II), SMRV, and retroviruses in general in a large panel of continuous primate cell lines to determine the potential risk for handling these cell lines. Regarding EBV, the inducibility of the lytic cycle was investigated by treatment of the latently infected cell lines with the phorbol ester 12-O-tetradecanoylphorbol-13acetate (TPA) and sodium butyrate (Na-butyrate).

\section{Materials and Methods}

2.1. Culture of Cell Lines. The continuous cell lines were provided for accessioning to the cell lines bank by the original or secondary investigators [9]. Cell lines were grown at $37^{\circ} \mathrm{C}$ in a humidified atmosphere of air containing $5 \% \mathrm{CO}_{2}$. The basic growth media (Invitrogen, Karlsruhe, Germany) were supplemented with $10 \%-20 \%$ fetal bovine serum (FBS) (Sigma, Deisenhofen, Germany). For growth factor-dependent cell lines, specific growth factors or conditioned media containing growth factors were added. No antibiotics were added to the cultures. All cell lines were free of mycoplasma and other bacterial, yeast, and fungi contaminations as tested by PCR and microbiological growth assays [10]. The authenticity of the cell lines was determined by DNA typing [11]. For the induction of the lytic cycle of EBV infection, PCR-positive cell lines were treated for 3 days with $10^{-7} \mathrm{M}$ TPA (Sigma) and $3 \mathrm{mM} \mathrm{Na-butyrate} \mathrm{(Sigma).}$

2.2. Western Blotting Analysis. A total of $1 \times 10^{6}$ cells were pelleted and washed with ice-cold phosphate buffered saline (PBS), resuspended in $30 \mu \mathrm{L}$ ice-cold protease inhibitor buffer containing $0.1 \mathrm{M} \mathrm{NaCl}, 10 \mathrm{mM}$ Tris- $\mathrm{HCl}, \mathrm{pH}$ 7.5,
$1 \mathrm{mM}$ EDTA, $1 \mu \mathrm{g} / \mathrm{mL}$ aprotinin, and $100 \mu \mathrm{g} / \mathrm{mL}$ phenylmethylsulfonyl fluoride and boiled for 10 minutes after addition of $30 \mu \mathrm{L} 2 \times$ SDS gel-loading buffer containing $125 \mathrm{mM}$ Tris- $\mathrm{HCl}, \mathrm{pH}$ 6.8, 4\% SDS, $20 \%$ glycerol $2 \% \beta-$ mercaptoethanol, and $0.1 \%$ bromophenol blue. Proteins were separated on $10 \%$ SDS-PAGE. Blotting and staining conditions were as described previously [12]. BZLF1 protein was detected using the mouse anti-ZEBRA antibody (DakoCytomation, Hamburg, Germany) diluted 1:100 in PBS and $5 \%$ FBS.

2.3. RT-ELISA. Most of the cell lines were analyzed for general infections with retroviruses applying an ELISA. Briefly, using $5 \mathrm{~mL}$ cell free culture supernatant, retrovirus particles were concentrated by ultracentrifugation at $100,000 \times \mathrm{g}$ or by polyethylene glycol precipitation and subsequent centrifugation at $800 \times \mathrm{g}$. The pellets were analyzed applying the Reverse Transcriptase Assay, nonradioactive, from Roche (Mannheim, Germany). In this assay, digoxigenin- and biotin-labeled desoxyuridine-triphosphates are incorporated in the presence of viral reverse transcriptase during the synthesis of a DNA strand along a synthetic target of single-stranded DNA molecules. The newly synthesized DNA is trapped on streptavidin-coated microtiter plates and subsequently detected immunologically by binding of peroxidase-labeled antidigoxigenin antibodies and visualized by color development and finally quantified by measuring the absorbance with an ELISA reader [13]. Two different buffers were used to detect $\mathrm{Mg}^{2+}$-dependent RT as well as $\mathrm{Mn}^{2+}$-dependent RT of mammalian C-type retroviruses.

2.4. In Situ Lysing Gel Analysis. Episomal and linear forms of EBV DNA were distinguished by horizontal gel electrophoresis according to Gardella et al. [14]. After electrophoresis, the separated DNA was blotted onto nylon filters (see Southern blot analysis) and the DNA was hybridized with a ${ }^{32} \mathrm{P}$ labeled ca. $37 \mathrm{~kb}$ DNA fragment of the $5^{\prime}$-region of EBV (cM-Sal A) [15].

2.5. Southern Blot Analysis. Genomic DNA of cell lines or DNA from EBV was extracted and purified using the PCR High Pure DNA kit from Roche. Fifteen $\mu \mathrm{g}$ of genomic DNA or EBV DNA from $24 \mathrm{~mL}$ supernatant of the B95-8 cell line were digested with $150 \mathrm{U}$ XhoI restriction enzyme over night. After electrophoresis, the separated DNA was blotted onto a nylon membrane and hybridized with various radioactively labeled cosmid probes from the EBV genome [15] as described earlier [16]. Probes for the $5^{\prime}$ - and $3^{\prime}$-region of the linear EBV genome were prepared by PCR. An 894 bp fragment of the $5^{\prime}$-region was amplified using the forward primer F-EBV1 $\left(5^{\prime}\right.$-AGG CAT TTA CGG TTA GTG TG$\left.3^{\prime}\right)$ and the reverse primer R-EBV1 ( $5^{\prime}$-CGG TCA GGATAG CAA GAA T- $3^{\prime}$ ). PCR was carried out with 35 cycles of 30 seconds at $95^{\circ} \mathrm{C}, 30$ seconds at $52^{\circ} \mathrm{C}$, and 1 minute at $72^{\circ} \mathrm{C}$ with hotstart Taq (TaKaRa, Lonza, Verviers, Belgium). A $619 \mathrm{bp}$ fragment of the $3^{\prime}$-region of the linear EBV genome was amplified using the forward primer F-EBV2 ( $5^{\prime}-$ ATC CTC AGG GCA GTG TGT CAG- ${ }^{\prime}$ ) and the reverse 
primer R-EBV2 (5'-CAA GCC GCA GCG ACT TTC-3'). PCR was carried out with 35 cycles of 30 seconds at $95^{\circ} \mathrm{C}$, 30 seconds at $59^{\circ} \mathrm{C}$, and 1 minute at $72^{\circ} \mathrm{C}$ with hotstart Taq. The PCR fragments were isolated from the gels and cloned into pGEM-T-easy vectors (Invitrogen). Aliquots of the clear lysates were labeled with ${ }^{32} \mathrm{P}$ by nick translation and hybridized to the Southern blots. Signals were detected with a phosphor imager (Molecular Dynamics, Sunnyvale, CA, USA).

2.6. PCR Assays. PCR or RT-PCR was applied for the detection of specific DNA or RNA sequences of the human pathogenic viruses EBV, HBV, HCV, HHV-8, HIV-1, HTLVI and -II, and SMRV. DNA sequences integrated into the cellular genome (proviruses) and episomal DNA of EBV and HHV-8 were detected using the PCR amplification method. DNA from cell lines was isolated applying the High Pure PCR Template Preparation kit from Roche. Specific oligonucleotide pairs from the gag region of HIV-1 (SK 38 and SK 39) [17], the pol region of HLTV-I/-II (SK 110 and SK 111) [18], the gag and env region of SMRV (F-SMRVenv, R-SMRV-env and F-SMRV-gag, R-SMRV-gag), from the EB2 (BMLF1) gene of EBV (TC 70 and TC 72) [19], and the putative minor capsid protein gene of HHV-8 (F- and R-HHV-8) [20] were used with the appropriate annealing temperatures in the PCR reaction (Table 1). The hot start PCR was either carried out by denaturing the reaction-mix which contains no Taq-polymerase for 7 minutes at $94^{\circ} \mathrm{C}$, subsequently adding the Taq-polymerase mix (1 U/reaction) during the following cycle step at $72^{\circ} \mathrm{C}$ for 3 minutes, annealing for 2 minutes at the appropriate temperature, and amplification at $72^{\circ} \mathrm{C}$ for 10 minutes, or by using hotstart Taq-polymerase with initial cycles according to the manufacturer's recommendations. After the initial cycle, 35 cycles were run at $95^{\circ} \mathrm{C}$ for 30 seconds, template specific annealing temperature for 30 seconds, and $72^{\circ} \mathrm{C}$ for 1 minute plus 2 seconds extension for each cycle. The amplified products were identified by agarose gel electrophoresis and visualized by ethidium bromide intercalation.

The active form of HBV was tested by organic extraction of DNA from $5 \mathrm{~mL}$ supernatant of the cell lines after enrichment of particles by ultracentrifugation ( 15 minutes at $100,000 \times \mathrm{g}$ ). PCR was carried out using forward and reverse primers from the conserved region of the precore/core protein gene to detect the different subtypes of HBV (Table 1). For the detection of the hepatitis B surface antigen coding region in cell line HEP-3B, a second primer pair was applied, consisting of the forward primer F-HBV-3 (5'-CAA GAT TCC TAT GGG AGT GGG CCT-3') and R-HBV-4 (5' -CTC TGC CGA TCC ATA CTG CGG AAC$\left.3^{\prime}\right)$.

For HCV detection, total RNA was isolated from cells by organic extraction with Trizol Reagent (Invitrogen) as described by the manufacturer. Five $\mu \mathrm{g}$ were reverse transcribed using random primers and SuperScript reverse transcriptase according to the recommendations of the manufacturer (Invitrogen). The equivalent of $1 \mu \mathrm{g}$ RNA was used for RT-PCR. The amplification was carried applying primers from the $5^{\prime}$ untranslated region $\left(5^{\prime}\right.$-UTR) of $\mathrm{HCV}$ [21] (Table 1).

In all PCR runs appropriate positive, negative, and internal controls were integrated in parallel reactions. As positive control for HIV, a plasmid containing the gag and pol region of HIV-1 was used. This was kindly provided by Dr. H. Hauser (Helmholtz Center for Infection Research, Braunschweig, Germany). As positive control for HTLV, we applied genomic DNA from the human T leukemia cell line MT-1. This cell line is infected with HTLV-I [22]. Regarding EBV and HHV-8, genomic DNA of the cell lines RAJI and CRO-AP2 were used as positive control DNA, respectively [20]. Active HBV reference plasma (subtypes ad and ay) were applied to establish the PCR procedure and used as positive controls. The plasma samples were obtained from the German National Reference Center for Virus Hepatitis (Göttingen, Germany). A plasmid containing the HCV 5'UTR was kindly provided by Professor Dr. M. Roggendorf from the National Reference Center for Hepatitis C (Essen, Germany).

Except for HHV-8 and SMRV, internal control DNA for each of the PCR assays was constructed starting from the PCR products of the positive control DNA. In general, DNA fragments were cloned into the PCR products to retain the target sequences of the respective primer pairs, but to obtain a PCR product which is significantly longer than the original PCR product of the wild type sequence. For HIV and HTLV, a $250 \mathrm{bp} \mathrm{HCV}$ positive control PCR fragment was inserted into the HIV and HTLV fragments, according to the "gene splicing by overlap extension" method described by Telenti et al. [23].

For HBV, the PCR product of the positive control reaction was ligated into the pGEM-T vector and a $445 \mathrm{bp}$ fragment was excised from the insert employing the restriction enzyme BglII. A 788 bp DNA fragment was isolated after digestion of the pGEM vector applying MboI. Both restriction enzymes produce the same sticky end sequences. Thus, the shortened and linearized vector containing the HBV PCR product ends can be ligated with the pGEM restriction fragment, transformed into E. coli, and the resulting plasmid can be used as internal control DNA for HBV. The fragment is $343 \mathrm{bp}$ longer than the wild type sequence. A similar strategy was applied for HCV. The PCR product from the positive control DNA was ligated into the pGEM-T vector and a $187 \mathrm{bp}$ fragment was excised using the restriction enzyme SmaI. pHSSE-1 was digested with RsaI and a $379 \mathrm{bp}$ fragment was extracted from the gel. Blunt-end ligation of the two DNA sequences and transformation into E. coli produced a plasmid containing a DNA sequence which can be amplified with the HCV primer and is $192 \mathrm{bp}$ longer than the wild type DNA.

2.7. Interphase FISH. One million cells were centrifuged at $200 \times \mathrm{g}$ for 5 minutes. The pellet was washed with $5 \mathrm{~mL}$ PBS, centrifuged again at $200 \times \mathrm{g}$ for 5 minutes, and the cells were resuspended in $0.5 \mathrm{~mL}$ PBS. One hundred $\mu \mathrm{l}$ of the cell suspension were centrifuged onto acid washed slides using a cytospin centrifuge. The slides were air-dried and the cells 
results from such misclassified cell lines might easily lead to false conclusions regarding the investigated tumor type.

Although the contamination with EBV is not detrimental to the cell culture, the effect of the contamination can be manifold. For example, the gene regulation of the cells can be influenced by transcription factors or altered methylation patterns, and central signal transduction pathways might be activated or inhibited by viral products (e.g., NF- $\kappa \mathrm{B}$, interferons) and might alter the physiology of the cells significantly.

We also investigated the presence of EBV infections in nonhematopoietic cell lines to determine whether some of the carcinoma cell lines of the above mentioned tissues might also be linked to EBV infections. In order to inhibit spread of the infections among cell cultures and for the classification of the cell lines into risk groups, it is important to know whether the infection is latent and no active viruses are produced or whether EBV particles are produced during the lytic phase of infection. In some cell lines the lytic phase of EBV infection can be induced, depending on the culture conditions. The possibility of induction of the release of active viruses was investigated by the treatment of the cells with TPA and Na-butyrate, because it is also relevant for the risk group classification of the cell lines.

The general infection status of cell lines with EBV was analyzed by PCR. This method detects linear genomes of the active EBV particles as well as EBV genomes integrated into the eukaryotic chromosomes and nonintegrated EBV episomes. The analyses revealed that 39 out of 465 primate cell lines contain sequences of the EBV genome (see Tables 2 and 3). Figure 1 shows a representative gel after performing EBV-PCR. All PCR positive human cell lines were established from B-lineage leukemia/lymphoma cells, natural killer cells, or are EBV transformed B-lymphoblastoid cells. No cell lines originating from other tissues were found to be $\mathrm{EBV}^{+}$. To demonstrate the integrity and the sensitivity of the PCR runs each sample was assayed in duplicate, one reaction without an internal control, and one reaction was spiked with the internal control DNA in a dilution that was close to the detection limit of the PCR assay (Figure 1).

A number of cell lines were examined for EBV infection by the originators of the cell lines or later on by other investigators. In the majority of cases the EBV status of the cell lines was determined immunologically by the detection of EBV nuclear antigen (EBNA), early antigen (EA), and/or viral capsid antigen (VCA). Concordance of our PCR results with data for protein expression given in the literature was found in nine cell lines (ARH-77, BONNA-1, HC1, JIYOYE, L-591, MEC-1, MEC-2, RAJI, and YT) [9, 25, 26]. The DOHH-2 cell line was originally described as EBV negative but was later on found to be EBV positive in EBNA immunofluorescence staining and PCR [27, 28]. In three cell lines (CRO-AP2, CRO-AP5, and HC-1) EBV sequences were demonstrated by Southern blotting [2931] and four cell lines were described to be established by immortalization with EBV particles from supernatant of the B95-8 cell line (EHEB, JVM-13, JVM-2, and JVM-3) $[32,33]$. The monkey cell line B95-8 is known to produce infectious EBV particles [34]. In contrast to our PCR results, the cell lines CI-1, NK-92, and TMM were specified as EBV negative as examined by EBNA and PCR assays [35-37]. Our PCR results were verified by FISH, in situ lysing gel analysis, Southern and Western blotting as described below and showed in at least two additional assays that all those cell lines are clearly EBV-positive (see Table 2).

The CI-1, DOHH-2, and TMM cell lines were positive in our PCR assay but showed weak or few signals in in situ lysing gel analysis and FISH (see below). This indicates that the EBV load of the cells is very low and that the expression of EBNA protein in these three cell lines was below the detection limit of the immunological assays. Thus, PCR is a convenient and reliable assay to detect EBV infections in cell cultures, provided that the appropriate control reactions including internal DNA controls are performed to avoid false positive and false negative results.

The activation of the lytic phase of the virus is usually closely connected with the production of infectious virus particles in the cells. The permissivity of a cell line relating to EBV is important to determine legally the risk group of the cell line as only cell cultures producing active viruses should represent an elevated risk. To identify the lytic phase of the EBV infections, we analyzed the expression of the ZEBRA protein (Bam HI Z Epstein-Barr replication activator) [38] by Western blotting applying an anti-ZEBRA monoclonal antibody. ZEBRA is the product of the BZLF1 gene and is a transcriptional activator that mediates a genetic switch between the latent and lytic states of EBV. ZEBRA binds to the promoters of genes involved in lytic DNA replication activating their transcription [39]. Thus, phorbol esters and Na-butyrate are among the most reproducible and most broadly applicable inducers of the lytic cycle of EBV [8]. However, not all latently infected lymphoblast cell lines can be induced by TPA and only a minority of the cells within a culture is inducible at all. In some human B-LCL about 10\% of the cells can be induced to permit lytic virus replication, whereas in a few others $20 \%-50 \%$ induced cells can be found [8]. Marmoset lymphoblasts seem to be more inducible, for example, the B95-8 cell line [40]. For this reason we used the B95-8 cell line as positive control to determine the efficiency of the induction with TPA/Na-butyrate.

All EBV PCR + cell lines were incubated with and without $10^{-7} \mathrm{M}$ TPA for 3 days and analyzed for ZEBRA expression. As shown in Table 2, five unstimulated cell lines exhibited a ZEBRA specific band of approximately $40 \mathrm{kDa}$ (B95-8, BD-215, L-591, NC-NC, and YT). The expression of the protein was weak in all five cell lines but increased after TPA/Na-butyrate stimulation. B95-8 and BD-215 increased strongly, whereas L-591 and YT increased only moderately. Six additional cell lines which showed no expression in the absence of TPA/Na-butyrate produced the ZEBRA protein in various amounts after induction of the lytic phase with TPA (EB-1, GRANTA-519, HC-1, IM-9, JIYOYE, and VAL). All other cell lines tested $(n=28)$ did not express the BZLF1 gene product even after stimulation with TPA/Na-butyrate. Figure 2 shows a representative Western blot with positive and negative cell lines. Lieberman et al. [41] showed that the ZEBRA protein is induced by TPA in RAJI cells. This was not confirmed in our screening for ZEBRA expression. RAJI is 
TABLE 2: EBV-PCR+ cell lines, BZLF1 expression detected by Western blotting, differentiation of episomal and linear EBV-DNA, EBV sequence pattern detected by Southern blotting, and episomal load determined by FISH.

\begin{tabular}{|c|c|c|c|c|c|c|c|c|}
\hline \multirow{2}{*}{ Cell line } & \multirow{2}{*}{ Cell type } & \multirow{2}{*}{$\mathrm{PCR}^{\mathrm{a}}$} & \multicolumn{2}{|c|}{ BZLF1 expr.a } & \multicolumn{2}{|c|}{ In situ lysing gel ${ }^{\mathrm{b}}$} & \multirow{2}{*}{ Southern blot ${ }^{c}$} & \multirow{2}{*}{ FISH $^{\mathrm{d}}$} \\
\hline & & & untr. & TPA & episomal & linear & & \\
\hline ARH-77 & B-LCL & + & - & - & $(+)$ & - & + & + \\
\hline B95-8 & marmoset monkey lymphocytes & + & + & + & ++ & +++ & + & +++ \\
\hline BD-215 & B-LCL & + & + & + & + & + & + & ++ \\
\hline BONNA-12 & hairy cell leukemia & + & - & - & ++ & + & + & $++(\mathrm{h})$ \\
\hline CI-1 & B cell lymphoma & + & - & - & + & - & n.d. & + \\
\hline COLO-720L & B-LCL & + & - & - & + & + & + & ++ \\
\hline CRO-AP2 & B cell lymphoma & + & - & - & $(+)$ & - & + & ++ \\
\hline CRO-AP5 & B cell lymphoma & + & - & - & $(+)$ & - & + & ++ \\
\hline DAUDI & Burkitt lymphoma & + & - & - & +++ & + & + & $++(\mathrm{h})$ \\
\hline DOHH-2 & B cell lymphoma & + & - & - & - & - & - & $+(\mathrm{f})$ \\
\hline EB-1 & Burkitt lymphoma & + & - & + & + & + & + & $++(\mathrm{h})$ \\
\hline EHEB & chronic B cell leukemia & + & - & - & + & $(+)$ & + & n.d. \\
\hline GRANTA-519 & B cell lymphoma & + & - & + & ++ & ++ & + & ++ \\
\hline $\mathrm{HC}-1$ & hairy cell leukemia & + & - & + & ++ & $(+)$ & + & ++++ \\
\hline IM-9 & B-LCL & + & - & + & +++ & - & + & ++++ \\
\hline JIYOYE & Burkitt lymphoma & + & - & + & ++ & ++ & + & +++ \\
\hline JVM-13 & chronic B cell leukemia & + & - & - & $++(2$ bands $)$ & - & + & ++++ \\
\hline JVM-2 & chronic B cell leukemia & + & - & - & + & + & + & +++ \\
\hline JVM-3 & chronic B cell leukemia & + & - & - & ++ & + & + & ++ \\
\hline L-591 & B-LCL & + & + & + & ++ & ++ & + & +++ \\
\hline LCL-HO & B-LCL & + & - & - & ++ & $(+)$ & + & +++ \\
\hline LCL-WEI & B-LCL & + & - & - & + & + & + & ++ \\
\hline MEC-1 & chronic B cell leukemia & + & - & - & + & + & + & $++(\mathrm{h})$ \\
\hline MEC-2 & chronic B cell leukemia & + & - & - & + & - & + & $++(\mathrm{h})$ \\
\hline NAMALWA & Burkitt lymphoma & + & - & - & - & - & $(+)$ & - \\
\hline NAMALWA.CSN/70 & Burkitt lymphoma & + & - & - & - & - & $(+)$ & - \\
\hline NAMALWA.IPN/45 & Burkitt lymphoma & + & - & - & - & - & $(+)$ & - \\
\hline NAMALWA.KN2 & Burkitt lymphoma & + & - & - & - & - & $(+)$ & - \\
\hline NAMALWA.PNT & Burkitt lymphoma & + & - & - & - & - & $(+)$ & - \\
\hline NC-NC & B-LCL & + & + & + & ++ & ++ & + & +++ \\
\hline NK-92 & natural killer lymphoma & + & - & - & + & + & + & + \\
\hline OCI-LY-19 & B cell lymphoma & + & - & - & - & - & - & - \\
\hline RAJI & Burkitt lymphoma & + & - & - & +++ & + & + & ++++ \\
\hline $\mathrm{RO}$ & B-LCL & + & - & - & + & - & + & ++ \\
\hline SD-1 & B-LCL & + & - & - & ++ & + & + & +++ \\
\hline T2 & human-human somatic cell hybrid & + & - & - & ++ & + & n.d. & n.d. \\
\hline TMM & B-LCL & + & - & - & $+(2$ bands $)$ & $(+)$ & + & +++ \\
\hline VAL & B cell lymphoma & + & - & + & $++(2$ bands $)$ & + & n.d. & $++(\mathrm{h})$ \\
\hline YT & T/natural killer cell leukemia & + & + & + & ++ & +++ & + & +++ \\
\hline
\end{tabular}

B-LCL: B-lymphoblastoid cell line; expr.: expression; n.d.: not determined; untr.: untreated.

a - : negative; + : positive.

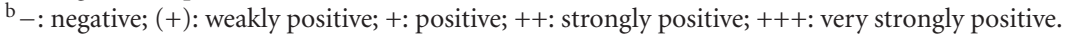

$c_{-}$: no bands visible; $(+)$: very weak signals; + : clear bands visible.

d episomal load detected by FISH: -: no episomes; +: low load; ++: load; +++: high load; ++++: very high load; (h): heterogenous distribution of the episomes among the cells; (f): only a few cells containing episomes. 
a nonproducer cell line with at least two deletions in the EBV genome and is defective for EBV DNA replication and late gene expression [8]. On the other hand, Di Francesco et al. [42] showed a weak induction of ZEBRA in Western blots after treatment with TPA in combination with n-butyrate, whereas further addition of cocain caused a high increase in ZEBRA expression. These contradictory findings can be explained by different cell sources or cell passage histories. However, importantly all studies demonstrated that ZEBRA was not expressed during normal cell culture, and thus, a production of viruses is very unlikely at nonstimulating conditions.

The EBV genome can be present in the host cells as covalently closed circles (episomes), as linear DNA of active viruses, or integrated into the host genome. The episomes are indicative for the latent infection status [8]. The EBV infected cells can harbor 1-10 episomes in low load cells or up to several hundred episomes in high load cells. EBV producer cell lines contain also linear double stranded DNA which is packaged into the virions. EBV genome integration was described only for a small number of cell lines. For example, the NAMALWA cell line and its subclones are described to contain an integrated EBV genome [43] and no episomes, whereas the RAJI cell line was reported to contain both, chromosomally integrated EBV genomes as well as episomes [44]. To distinguish between the linear DNA of active viruses, episomal DNA of EBV-infected cell cultures, and solely integrated EBV genomes, we performed a variation of a Southern blot analysis as described by Gardella et al. [14].

The autoradiograms showed the episomal DNA as clearcut bands whereas the linear DNA usually formed distinct bands within a smear of DNA (Figure 3). The episomal as well as the linear DNA of the cell lines examined showed different migrations indicating different EBV clones. Except for the NAWALWA cell line and its subclones, DOHH-2, and OCI-LY19, all EBV PCR positive cell lines showed at least one band of episomal EBV genomes (Table 2). As no denaturing conditions were applied in the in situ lysing gels, different sequences of the EBV strains can result in different conformations and mobilities of the episomes. The cell lines COLO-720L, IM-9, JVM-13, LCL-HO, TMM, and VAL displayed two episomal DNA bands. The intensities of the episomal bands were almost identical only in the cell line JVM-13. The existence of two EBV clones in one cell line can be explained by three assumptions: (i) two different EBV clones simultaneously infected the cell which led to the establishment of the cell line, (ii) the cell line was established from two or more different cells of the patient harboring different EBV clones (oligoclonality), or (iii) single and duplicated episomes are present in the nuclei of the cell lines.

The NK-92 and TMM cell lines were described to be EBV negative according to EBNA detection assay and PCR, respectively [35, 37]. Both cell lines showed EBV specific episomal DNA in the in situ lysing gels. This confirmed the results of the PCR assay as discussed above. Concerning the NAMALWA cell lines, no episomal DNA bands were expected, because the EBV DNA was described to be

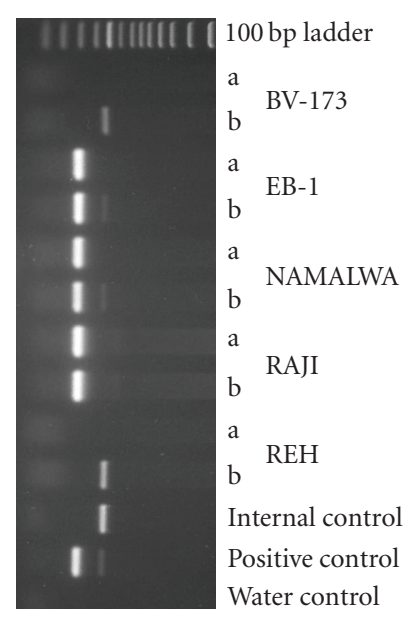

FIgURE 1: PCR analysis of EBV status in cell lines. Shown is an ethidium bromide-stained gel containing the reaction products following PCR amplification with the primers F-EBV and R-EBV (see Table 1). Products of $265 \mathrm{bp}$ were obtained. Shown are various examples of EBV-negative and EBV-positive cell lines. Two paired PCR reactions were performed: one PCR reaction contained an aliquot of the sample only (a) and the second reaction contained the sample under study plus the control DNA as internal standard, which results in an amplified product size of $445 \mathrm{bp}$ (b). The cell cultures EB-1, NAMALWA, and RAJI are EBV-positive; the cell cultures BV-173 and REH, both B-cell precursor leukemia cell lines, are EBV-negative.

integrated into the eukaryotic genome [45]. Since no linear DNA was detected, the integrated genome is not transcribed in those cell lines. DOHH-2 and OCI-LY-19 might also only contain integrated EBV genomes, but fluorescence in situ hybridization (FISH) indicates that the number of EBV episomes in a cell culture is too low to be detected by in situ lysing gels (see below).

The intensities of the episomal bands in the in situ lysing gels were highly variable among the cell lines but were constant for a given cell line, indicating that the EBV loads are different in the cell lines examined. The highest episomal loads were found in the cell lines DAUDI, IM-9, L-591, RAJI, and SD-1. Of these, only the L-591 cell line expressed BZLF1 constitutively and IM-9 expressed the protein after stimulation with TPA and Na-butyrate. The other BZLF1 expressing cell lines displayed a lower number of episomes. This indicates that the lytic cycle induction is completely indepentent from the number of episomes present in the nuclei. High episomal loads were described for the cell line DAUDI and RAJI, which carry 100-200 and 50-60 viral copies per cell, respectively $[23,46]$. Based on the intensities of the EBV-specific bands in the autoradiograms of the in situ lysing gel assays, the numbers of episomes in IM-9 and SD-1 were comparable to those of DAUDI or RAJI, respectively. All other cell lines were low load cell lines with 1-10 EBV copies per cell compared to the high load cell lines mentioned above (Figure 3).

In order to obtain more quantitative data on the EBV load of the $\mathrm{EBV}^{+}$cell lines, we performed single cell analyses 
TABLE 3: List of cell lines tested for RT activity by ELISA, and for the presence of EBV, HBV, HCV, HIV-1, HTLV-I/-II, and SMRV.

\begin{tabular}{|c|c|c|c|c|c|c|c|c|}
\hline Cell line & Zelltyp & RT-ELISA & $\mathrm{HCV}$ & EBV & HBV & HIV & HTLV & SMRV \\
\hline 22RV1 & Prostate cancer & & - & - & - & - & - & - \\
\hline $23132 / 87$ & Gastric adenocarcinoma & - & - & - & - & - & - & - \\
\hline 293 & Embryonal kidney & - & - & - & - & - & - & - \\
\hline $293 \mathrm{~T}$ & Embryonal kidney & & - & - & - & - & - & - \\
\hline 380 & Pre B cell leukemia & - & - & - & - & - & - & - \\
\hline 42-MG-BA & Glioma & - & - & - & - & - & - & - \\
\hline 5637 & Urinary bladder carcinoma & - & - & - & - & - & - & - \\
\hline $639-\mathrm{V}$ & Urinary bladder carcinoma & - & - & - & - & - & - & \\
\hline $647-\mathrm{V}$ & Urinary bladder carcinoma & - & - & - & - & - & - & - \\
\hline 697 & Pre B cell leukemia & - & - & - & - & - & - & - \\
\hline $8305 \mathrm{C}$ & Thyroid carcinoma & - & - & - & - & - & - & - \\
\hline $8505 \mathrm{C}$ & Thyroid carcinoma & - & - & - & - & - & - & - \\
\hline 8-MG-BA & Glioma & - & - & - & - & - & - & \\
\hline A-204 & Rhabdomyosarcoma & - & - & - & - & - & - & - \\
\hline A-427 & Lung carcinoma & - & - & - & - & - & - & - \\
\hline A-431 & Epidermoid carcinoma & - & - & - & - & - & - & - \\
\hline A-498 & Kidney carcinoma & - & - & - & - & - & - & - \\
\hline A-549 & Lung carcinoma & - & - & - & - & - & - & - \\
\hline AC-1M32 & Choriocarcinoma-trophoblast hybrid & & - & - & - & - & - & - \\
\hline AC-1M46 & Choriocarcinoma-trophoblast hybrid & & - & - & - & - & - & - \\
\hline AC-1M59 & Choriocarcinoma-trophoblast hybrid & & - & - & - & - & - & - \\
\hline AC-1M81 & Choriocarcinoma-trophoblast hybrid & & - & - & - & - & - & - \\
\hline AC-1M88 & Choriocarcinoma-trophoblast hybrid & & - & - & - & - & - & - \\
\hline ACH1P & Choricarcinoma-trophoblast hybrid & & - & - & - & - & - & - \\
\hline ALL-SIL & T cell leukemia & & - & - & - & - & - & - \\
\hline AML-193 & Acute myeloid leukemia & & - & - & - & - & - & - \\
\hline AMO-1 & Plasmocytoma & & - & - & - & - & - & - \\
\hline AN3-CA & Endometrial adenocarcinoma & - & - & - & - & - & - & - \\
\hline AP-1060 & Acute myeloid leukemia & & - & - & - & - & - & - \\
\hline ARH-77 & Multiple myeloma & & - & + & - & - & - & - \\
\hline BC-3C & Urinary bladder transitional cell carcinoma & & - & - & - & - & - & - \\
\hline B-CPAP & Thyroid carcinoma & - & - & - & - & - & - & - \\
\hline BD-215 & B lymphoblastoid cells & - & - & + & - & - & - & - \\
\hline BE-13 & T cell leukemia & - & - & - & - & - & - & - \\
\hline BEN & Lung carcinoma & & - & - & - & - & - & - \\
\hline BEN-MEN-1 & Benign meningioma & & - & - & - & - & - & - \\
\hline BEWO & Choriocarcinoma & & - & - & - & - & - & - \\
\hline BFTC-905 & Urinary bladder transitional cell carcinoma & - & - & - & - & - & - & - \\
\hline BFTC-909 & Kidney transitional cell carcinoma & - & - & - & - & - & - & - \\
\hline BHT-101 & Thyroid carcinoma & - & - & - & - & - & - & - \\
\hline BHY & Oral squamous carcinoma & - & - & - & - & - & - & - \\
\hline BL-2 & Burkitt lymphoma & & - & - & - & - & - & - \\
\hline BL-41 & Burkitt lymphoma & - & - & - & - & - & - & \\
\hline BL-70 & Burkitt lymphoma & - & - & - & - & - & - & - \\
\hline BLUE-1 & Burkitt lymphoma & & - & - & - & - & - & - \\
\hline BM-1604 & Prostate carcinoma (derivative of DU-145) & - & - & - & - & - & - & - \\
\hline BONNA-12 & Hairy cell leukemia & - & - & + & - & - & - & - \\
\hline BPH-1 & Prostate benign hyperplasia & - & - & - & - & - & - & - \\
\hline BT-474 & Breast ductal carcinoma & - & - & - & - & - & - & - \\
\hline BT-B & Cervix carcinoma (subclone of HELA) & - & - & - & - & - & - & - \\
\hline BV-173 & Pre B cell leukemia & - & - & - & - & - & - & - \\
\hline C-433 & Ewing's sarcoma & - & - & - & - & - & - & - \\
\hline CA-46 & Burkitt lymphoma & - & - & - & - & - & - & - \\
\hline CACO-2 & Colon adenocarcinoma & - & - & - & - & - & - & - \\
\hline CADO-ES1 & Ewing's sarcoma & - & - & - & - & - & - & - \\
\hline
\end{tabular}


Table 3: Continued.

\begin{tabular}{|c|c|c|c|c|c|c|c|c|}
\hline Cell line & Zelltyp & RT-ELISA & $\mathrm{HCV}$ & EBV & HBV & HIV & HTLV & SMRV \\
\hline CAKI-1 & Kidney carcinoma & - & - & - & - & - & - & - \\
\hline CAKI-2 & Kidney carcinoma & - & - & - & - & - & - & - \\
\hline CAL-120 & Breast adenocarcinoma & & - & - & - & - & - & \\
\hline CAL-12T & Non-small cell lung carcinoma & & - & - & - & - & - & - \\
\hline CAL-148 & Breast adenocarcinoma & & - & - & - & - & - & - \\
\hline CAL-27 & Tongue squamous cell carcinoma & & - & - & - & - & - & - \\
\hline CAL-29 & Urinary bladder transitional cell carcinoma & & - & - & - & - & - & - \\
\hline CAL-33 & Tongue squamous cell carcinoma & & - & - & - & - & - & - \\
\hline CAL-39 & Vulva carcinoma & - & - & - & - & - & - & - \\
\hline CAL-51 & Breast carcinoma & - & - & - & - & - & - & - \\
\hline CAL-54 & Kidney carcinoma & - & - & - & - & - & - & - \\
\hline CAL-62 & Thyroid anaplastic carcinoma & & - & - & - & - & - & - \\
\hline CAL-72 & Osteosarcoma & & - & - & - & - & - & - \\
\hline CAL-78 & Chondrosarcoma & & - & - & - & - & - & - \\
\hline CAL-85-1 & Breast adenocarcinoma & & - & - & - & - & - & - \\
\hline CAPAN-1 & Pancreas adenocarcinoma & - & - & - & - & - & - & - \\
\hline CAPAN-2 & Pancreas adenocarcinoma & - & - & - & - & - & - & - \\
\hline CCRF-CEM & $\mathrm{T}$ cell leukemia & - & - & - & - & - & - & - \\
\hline CGTH-W-1 & Thyroid carcinoma & - & - & - & - & - & - & - \\
\hline CHP-126 & Neuroblastoma & - & - & - & - & - & - & - \\
\hline CI-1 & B cell lymphoma & & - & + & - & - & - & - \\
\hline CL-11 & Colon carcinoma & & - & - & - & - & - & - \\
\hline CL-14 & Colon carcinoma & & - & - & - & - & - & \\
\hline CL-34 & Colon carcinoma & & - & - & - & - & - & - \\
\hline CL-40 & Colon carcinoma & & - & - & - & - & - & - \\
\hline CMK & Acute megakaryocytic leukemia & - & - & - & - & - & - & - \\
\hline CML-T1 & $\mathrm{T}$ cell leukemia & - & - & - & - & - & - & - \\
\hline COLO-206F & Colon carcinoma & - & - & - & - & - & - & - \\
\hline COLO-320 & Colon adenocarcinoma & - & - & - & - & - & - & - \\
\hline COLO-677 & Small cell lung carcinoma & - & - & - & - & - & - & - \\
\hline COLO-678 & Colon carcinoma & - & - & - & - & - & - & \\
\hline COLO-679 & Melanoma & - & - & - & - & - & - & - \\
\hline COLO-680N & Esophagus squamous cell carcinoma & - & - & - & - & - & - & - \\
\hline COLO-699 & Lung adenocarcinoma & - & - & - & - & - & - & - \\
\hline COLO-704 & Ovary adenocarcinoma & - & - & - & - & - & - & - \\
\hline COLO-720L & B lymphoblastoid cells & - & - & + & - & - & - & - \\
\hline COLO-783 & Melanoma & - & - & - & - & - & - & - \\
\hline COLO-800 & Melanoma & - & - & - & - & - & - & - \\
\hline COLO-818 & Melanoma & - & - & - & - & - & - & - \\
\hline COLO-824 & Breast carcinoma & - & - & - & - & - & - & - \\
\hline COLO-849 & Melanoma & - & - & - & - & - & - & - \\
\hline CPC-N & Small cell lung carcinoma & - & - & - & - & - & - & - \\
\hline CRO-AP2 & B cell lymphoma & - & - & + & - & - & - & - \\
\hline CRO-AP3 & B cell lymphoma & - & - & - & - & - & - & - \\
\hline CRO-AP5 & B cell lymphoma & - & - & + & - & - & - & \\
\hline CRO-AP6 & B cell lymphoma & & - & - & - & - & - & - \\
\hline CTV-1 & $\mathrm{T}$ cell leukemia & - & - & - & - & - & - & - \\
\hline CX-1 & Colon adenocarcinoma & - & - & - & - & - & - & - \\
\hline DAN-G & Pancreas carcinoma & - & - & - & - & - & - & - \\
\hline DAUDI & Burkitt lymphoma & - & - & + & - & - & - & - \\
\hline DB & B cell lymphoma & & - & - & - & - & - & - \\
\hline DBTRG-05MG & Glioblastoma & - & - & - & - & - & - & - \\
\hline DEL & Malignant histiocytosis & - & - & - & - & - & - & - \\
\hline DERL-2 & $\mathrm{T}$ cell lymphoma & & - & - & - & - & - & - \\
\hline DERL-7 & $\mathrm{T}$ cell lymphoma & & - & - & - & - & - & - \\
\hline
\end{tabular}


Table 3: Continued.

\begin{tabular}{|c|c|c|c|c|c|c|c|c|}
\hline Cell line & Zelltyp & RT-ELISA & $\mathrm{HCV}$ & EBV & HBV & HIV & HTLV & SMRV \\
\hline DG-75 & Burkitt lymphoma & - & - & - & - & - & - & - \\
\hline DK-MG & Glioblastoma & - & - & - & - & - & - & - \\
\hline DLD-1 & Colon adenocarcinoma & - & - & - & - & - & - & - \\
\hline DM-3 & Sarcomatoid mesothelioma & & - & - & - & - & - & - \\
\hline DND-41 & $\mathrm{T}$ cell leukemia & & - & - & - & - & - & \\
\hline DOGKIT & Burkitt lymphoma & & - & - & - & - & - & - \\
\hline DOGUM & Burkitt lymphoma & & - & - & - & - & - & - \\
\hline DOHH-2 & B cell lymphoma & - & - & + & - & - & - & - \\
\hline DU-145 & Prostate carcinoma & - & - & - & - & - & - & - \\
\hline DU-4475 & Breast carcinoma & - & - & - & - & - & - & - \\
\hline DV-90 & Lung adenocarcinoma & - & - & - & - & - & - & - \\
\hline EB-1 & Burkitt lymphoma & - & - & + & - & - & - & - \\
\hline ECV-304 & Urinary bladder carcinoma (derivative of T-24) & - & - & - & - & - & - & - \\
\hline EFE-184 & Endometrium carcinoma & - & - & - & - & - & - & - \\
\hline EFM-19 & Breast carcinoma & - & - & - & - & - & - & - \\
\hline EFM-192A & Breast carcinoma & - & - & - & - & - & - & - \\
\hline EFM-192B & Breast carcinoma & - & - & - & - & - & - & - \\
\hline EFM-192C & Breast carcinoma & - & - & - & - & - & - & - \\
\hline EFO-21 & Ovary cystadenocarcinoma & - & - & - & - & - & - & - \\
\hline EFO-27 & Ovary adenocarcinoma & - & - & - & - & - & - & - \\
\hline EGI-1 & Bile duct carcinoma & - & - & - & - & - & - & - \\
\hline EHEB & Chronic B cell leukemia & - & - & + & - & - & - & - \\
\hline EJM & Multiple myeloma & & - & - & - & - & - & - \\
\hline EM-2 & Chronic myeloid leukemia & - & - & - & - & - & - & - \\
\hline EM-3 & Chronic myeloid leukemia & - & - & - & - & - & - & - \\
\hline $\mathrm{EN}$ & Endometrial carcinoma & & - & - & - & - & - & - \\
\hline EOL-1 & Eosinophilic leukemia & - & - & - & - & - & - & - \\
\hline EPLC-272H & Lung carcinoma & - & - & - & - & - & - & - \\
\hline ESS-1 & Endometrial stromal sarcoma & & - & - & - & - & - & - \\
\hline EVSA-T & Breast carcinoma & - & - & - & - & - & - & - \\
\hline $\mathrm{F}-36 \mathrm{P}$ & Acute myeloid leukemia & & - & - & - & - & - & - \\
\hline FKH-1 & Acute myeloid leukemia & & - & - & - & - & - & - \\
\hline FU-OV-1 & Ovarian cancer & & - & - & - & - & - & - \\
\hline GAMG & Glioma & - & - & - & - & - & - & - \\
\hline GDM-1 & Acute myelomonocytic leukemia & - & - & - & - & - & - & - \\
\hline GF-D8 & Acute myeloid leukemia & & - & - & - & - & - & \\
\hline GIRARDI HEART C2 & Cervix carcinoma (subclone of HELA) & - & - & - & - & - & - & - \\
\hline GIRARDI HEART C7 & Cervix carcinoma (subclone of HELA) & - & - & - & - & - & - & - \\
\hline GMS-10 & Glioblastoma & - & - & - & - & - & - & - \\
\hline GOS-3 & Astrocytoma/oligodendroglioma & - & - & - & - & - & - & - \\
\hline GRANTA-519 & B cell lymphoma & - & - & + & - & - & - & - \\
\hline GUMBUS & Burkitt lymphoma & & - & - & - & - & - & - \\
\hline H-1184 & Lung small cell carcinoma & & - & - & - & - & - & - \\
\hline H-1339 & Lung small cell carcinoma & & - & - & - & - & - & - \\
\hline H-1963 & Small cell lung carcinoma & & - & - & - & - & - & - \\
\hline H-209 & Lung small cell carcinoma & & - & - & - & - & - & - \\
\hline H-2171 & Small cell lung carcinoma & & - & - & - & - & - & - \\
\hline HAL-01 & B cell precursor leukemia & & - & - & - & - & - & - \\
\hline HC-1 & Hairy cell leukemia & - & - & + & - & - & - & - \\
\hline HCC-1143 & Breast carcinoma & & - & - & - & - & - & - \\
\hline HCC-15 & Non-small cell lung carcinoma & & - & - & - & - & - & - \\
\hline HCC-1599 & Breast carcinoma & & - & - & - & - & - & - \\
\hline HCC-1937 & Breast carcinoma & & - & - & - & - & - & - \\
\hline HCC-33 & Lung small cell carcinoma & & - & - & - & - & - & - \\
\hline HCC-366 & Lung squamous adenocarcinoma & & - & - & - & - & - & - \\
\hline
\end{tabular}


Table 3: Continued.

\begin{tabular}{|c|c|c|c|c|c|c|c|c|}
\hline Cell line & Zelltyp & RT-ELISA & $\mathrm{HCV}$ & EBV & $\mathrm{HBV}$ & HIV & HTLV & SMRV \\
\hline HCC-44 & Non-small cell lung carcinoma & & - & - & - & - & - & - \\
\hline HCC-78 & Non-small cell lung carcinoma & & - & - & - & - & - & - \\
\hline HCC-827 & Non-small cell lung carcinoma & & - & - & - & - & - & - \\
\hline HCEC-12 & Cornea endothelium & & - & - & - & - & - & - \\
\hline HCEC-B4G12 & Cornea endothelium & & - & - & - & - & - & - \\
\hline HCEC-H9C1 & Cornea endothelium & & - & - & - & - & - & - \\
\hline HCT-116 & Colon carcinoma & & - & - & - & - & - & \\
\hline HCT-15 & Colon adenocarcinoma & - & - & - & - & - & - & - \\
\hline HDLM-2 & Hodgkin lymphoma & - & - & - & - & - & - & - \\
\hline HD-MY-Z & Hodgkin lymphoma & - & - & - & - & - & - & - \\
\hline HDQ-P1 & Breast carcinoma & & - & - & - & - & - & - \\
\hline HEL & Erythroleukemia & - & - & - & - & - & - & - \\
\hline HELA & Cervix carcinoma & - & - & - & - & - & - & - \\
\hline HELA-S3 & Cervix carcinoma (subclone of HELA) & - & - & - & - & - & - & - \\
\hline HEP-3B & Hepatocellular carcinoma & - & - & - & + & - & - & - \\
\hline HEP-G2 & Hepatocellular carcinoma & - & - & - & - & - & - & \\
\hline HL-60 & Acute myeloid leukemia & - & - & - & - & - & - & - \\
\hline HMC-1 & Mast cell leukemia & & - & - & - & - & - & - \\
\hline $\mathrm{HN}$ & Oral squamous carcinoma & - & - & - & - & - & - & - \\
\hline HNT-34 & Acute myeloid leukemia & & - & - & - & - & - & - \\
\hline HPB-ALL & T cell leukemia & & - & - & - & - & - & \\
\hline HSB-2 & $\mathrm{T}$ cell leukemia & - & - & - & - & - & - & - \\
\hline HT & B cell lymphoma & & - & - & - & - & - & - \\
\hline HT-1080 & Fibrosarcoma & - & - & - & - & - & - & \\
\hline HT-1376 & Bladder carcinoma & - & - & - & - & - & - & - \\
\hline HT-29 & Colon adenocarcinoma & - & - & - & - & - & - & - \\
\hline HTC-C3 & Thyroid carcinoma & & - & - & - & - & - & - \\
\hline HUP-T3 & Pancreas carcinoma & - & - & - & - & - & - & \\
\hline HUP-T4 & Pancreas carcinoma & - & - & - & - & - & - & - \\
\hline IGR-1 & Melanoma & - & - & - & - & - & - & - \\
\hline IGR-37 & Melanoma & - & - & - & - & - & - & - \\
\hline IGR-39 & Melanoma & - & - & - & - & - & - & - \\
\hline IM-9 & Multiple myeloma & - & - & + & - & - & - & - \\
\hline IMR-32 & Neuroblastoma & - & - & - & - & - & - & - \\
\hline IPC-298 & Melanoma & - & - & - & - & - & - & - \\
\hline JAR & Choriocarcinoma & & - & - & - & - & - & - \\
\hline JEG-3 & Choriocarcinoma & & - & - & - & - & - & - \\
\hline JEKO-1 & B cell lymphoma & & - & - & - & - & - & - \\
\hline JIMT-1 & Breast carcinoma & & - & - & - & - & - & - \\
\hline JIYOYE & B cell lymphoma & & - & + & - & - & - & - \\
\hline JJN-3 & Plasma cell leukemia & & - & - & - & - & - & - \\
\hline $\mathrm{JK}-1$ & Chronic myeloid leukemia & - & - & - & - & - & - & - \\
\hline JL-1 & Epitheloid mesothelioma & & - & - & - & - & - & - \\
\hline JMSU-1 & Urinary bladder carcinoma & & - & - & - & - & - & - \\
\hline JOSK-I & Histiocytic lymphoma (derivative of U-937) & - & - & - & - & - & - & \\
\hline JOSK-M & Histiocytic lymphoma (derivative of U-937) & - & - & - & - & - & - & - \\
\hline JURKAT & T cell leukemia & - & - & - & - & - & - & - \\
\hline JURL-MK1 & Chronic myeloid leukemia in blast crisis & & - & - & - & - & - & - \\
\hline JURL-MK2 & Chronic myeloid leukemia in blast crisis & & - & - & - & - & - & - \\
\hline JVM-13 & Chronic B cell leukemia & - & - & + & - & - & - & - \\
\hline JVM-2 & Chronic B cell leukemia & - & - & + & - & - & - & - \\
\hline JVM-3 & Chronic B cell leukemia & - & - & + & - & - & - & - \\
\hline K-562 & Chronic myeloid leukemia & - & - & - & - & - & - & - \\
\hline KARPAS-1106P & B cell lymphoma & & - & - & - & - & - & - \\
\hline KARPAS-231 & B cell leukemia & & - & - & - & - & - & - \\
\hline
\end{tabular}


Table 3: Continued.

\begin{tabular}{|c|c|c|c|c|c|c|c|c|}
\hline Cell line & Zelltyp & RT-ELISA & $\mathrm{HCV}$ & EBV & HBV & HIV & HTLV & SMRV \\
\hline KARPAS-299 & T cell lymphoma & - & - & - & - & - & - & \\
\hline KARPAS-422 & B cell lymphoma & - & - & - & - & - & - & - \\
\hline KARPAS-45 & $\mathrm{T}$ cell leukemia & - & - & - & - & - & - & - \\
\hline KARPAS-620 & Plasma cell leukemia & & - & - & - & - & - & - \\
\hline KASUMI-1 & Acute myeloid leukemia & + & - & - & - & - & - & - \\
\hline KASUMI-2 & B cell precursor leukemia & & - & - & - & - & - & - \\
\hline KB & Cervix carcinoma (subclone of HELA) & - & - & - & - & - & - & - \\
\hline KB-3-1 & Cervix carcinoma (subclone of HELA) & - & - & - & - & - & - & - \\
\hline $\mathrm{KB}-\mathrm{V} 1$ & Cervix carcinoma (subclone of HELA) & - & - & - & - & - & - & - \\
\hline KCI-MOH1 & Pancreatic adenocarcinoma & & - & - & - & - & - & - \\
\hline KCL-22 & Chronic myeloid leukemia in blast crisis & & - & - & - & - & - & \\
\hline KE-37 & $\mathrm{T}$ cell leukemia & - & - & - & - & - & - & - \\
\hline KELLY & Neuroblastoma & - & - & - & - & - & - & - \\
\hline KG-1 & Acute myeloid leukemia & - & - & - & - & - & - & - \\
\hline KG-1a & Acute myeloid leukemia & - & - & - & - & - & - & - \\
\hline KM-H2 & Hodgkin lymphoma & - & - & - & - & - & - & \\
\hline KMOE-2 & Acute erythremia & - & - & - & - & - & - & - \\
\hline KMS-12-BM & Myeloma & & - & - & - & - & - & - \\
\hline KMS-12-PE & Multiple myeloma & & - & - & - & - & - & - \\
\hline KOPN-8 & $\mathrm{B}$ cell precursor leukemia & & - & - & - & - & - & - \\
\hline KPL-1 & Breast carcinoma & - & - & - & - & - & - & - \\
\hline KU-19-19 & Urinary bladder carcinoma & - & - & - & - & - & - & - \\
\hline KU-812 & Chronic myeloid leukemia in myeloid blast crisis & - & - & - & - & - & - & - \\
\hline KYO-1 & Chronic myeloid leukemia in blast crisis & & - & - & - & - & - & - \\
\hline KYSE-140 & Esophageal carcinoma & - & - & - & - & - & - & - \\
\hline KYSE-150 & Esophageal carcinoma & - & - & - & - & - & - & - \\
\hline KYSE-180 & Esophageal carcinoma & - & - & - & - & - & - & - \\
\hline KYSE-270 & Esophageal carcinoma & - & - & - & - & - & - & - \\
\hline KYSE-30 & Esophageal carcinoma & - & - & - & - & - & - & - \\
\hline KYSE-410 & Esophageal carcinoma & - & - & - & - & - & - & - \\
\hline KYSE-450 & Esophageal carcinoma & - & - & - & - & - & - & - \\
\hline KYSE-510 & Esophageal carcinoma & - & - & - & - & - & - & - \\
\hline KYSE-520 & Esophageal carcinoma & - & - & - & - & - & - & - \\
\hline KYSE-70 & Esophageal carcinoma & - & - & - & - & - & - & - \\
\hline L-1236 & Hodgkin lymphoma & & - & - & - & - & - & \\
\hline L-363 & Plasma cell leukemia & - & - & - & - & - & - & - \\
\hline L-428 & Hodgkin lymphoma & - & - & - & - & - & - & - \\
\hline L-540 & Hodgkin lymphoma & - & - & - & - & - & - & - \\
\hline L-591 & B lymphoblastoid cells & & - & + & - & - & - & - \\
\hline L-82 & Anaplastic large cell lymphoma & & - & - & - & - & - & \\
\hline LAMA-84 & Chronic myeloid leukemia & - & - & - & - & - & - & - \\
\hline LAMA-87 & Chronic myeloid leukemia in blast crisis & - & - & - & - & - & - & - \\
\hline LCLC-103H & Lung carcinoma & - & - & - & - & - & - & - \\
\hline LCLC-97TM1 & Lung carcinoma & - & - & - & - & - & - & - \\
\hline LCL-HO & B lymphoblastoid cells & - & - & + & - & - & - & + \\
\hline LCL-WEI & B lymphoblastoid cells & - & - & + & - & - & - & - \\
\hline LN-405 & Astrocytoma & - & - & - & - & - & - & - \\
\hline LNCAP & Prostata carcinoma & - & - & - & - & - & - & - \\
\hline LOUCY & $\mathrm{T}$ cell leukemia & - & - & - & - & - & - & - \\
\hline LOU-NH91 & Lung carcinoma & - & - & - & - & - & - & - \\
\hline LOVO & Colon adenocarcinoma & - & - & - & - & - & - & \\
\hline LP-1 & Multiple myeloma & - & - & - & - & - & - & - \\
\hline LXF-289 & Lung adenocarcinoma & - & - & - & - & - & - & - \\
\hline M-07e & Acute megakaryoblastic leukemia & - & - & - & - & - & - & - \\
\hline MB-1 & Anaplastic thyroid carcinoma & & - & - & - & - & - & - \\
\hline
\end{tabular}


Table 3: Continued.

\begin{tabular}{|c|c|c|c|c|c|c|c|c|}
\hline Cell line & Zelltyp & RT-ELISA & $\mathrm{HCV}$ & EBV & HBV & HIV & HTLV & SMRV \\
\hline MC-116 & B cell lymphoma & - & - & - & - & - & - & - \\
\hline MCF-7 & Breast adenocarcinoma & - & - & - & - & - & - & - \\
\hline MDA-MB-453 & Breast carcinoma & - & - & - & - & - & - & - \\
\hline ME-1 & Acute myeloid leukemia & & - & - & - & - & - & - \\
\hline MEC-1 & Chronik B cell leukemia & & - & + & - & - & - & - \\
\hline MEC-2 & Chronic B cell leukemia & & - & + & - & - & - & - \\
\hline MEG-01 & chronic myeloid leukemia in megakaryocytic blast crisis & - & - & - & - & - & - & - \\
\hline MEL-HO & Melanoma & - & - & - & - & - & - & - \\
\hline MEL-JUSO & Melanoma & - & - & - & - & - & - & - \\
\hline MFE-280 & Endometrium carcinoma & - & - & - & - & - & - & - \\
\hline MFE-296 & Endometrium carcinoma & - & - & - & - & - & - & - \\
\hline MFE-319 & Endometrium carcinoma & - & - & - & - & - & - & - \\
\hline MFM-223 & Breast carcinoma & - & - & - & - & - & - & - \\
\hline MHH-CALL-2 & B cell precursor leukemia & - & - & - & - & - & - & - \\
\hline MHH-CALL-3 & B cell precursor leukemia & - & - & - & - & - & - & - \\
\hline MHH-CALL-4 & B cell precursor leukemia & - & - & - & - & - & - & - \\
\hline MHH-ES-1 & Ewing's osteosarcoma & - & - & - & - & - & - & - \\
\hline MHH-NB-11 & Neuroblastoma & - & - & - & - & - & - & \\
\hline MHH-PREB-1 & B cell lymphoma & - & - & - & - & - & - & - \\
\hline MKN-45 & Gastric carcinoma & - & - & - & - & - & - & - \\
\hline ML-1 & Follicular thyroid carcinoma & & - & - & - & - & - & - \\
\hline ML-2 & Acute myelomonocytic leukemia & - & - & - & - & - & - & - \\
\hline MN-60 & B cell lymphoma & - & - & - & - & - & - & - \\
\hline MOLM-13 & Acute myeloid leukemia & & - & - & - & - & - & - \\
\hline MOLM-16 & Acute myeloid leukemia & & - & - & - & - & - & - \\
\hline MOLM-20 & Chronic myeloid leukemia & & - & - & - & - & - & - \\
\hline MOLM-6 & Chronic myeloid leukemia in blast crisis & & - & - & - & - & - & \\
\hline MOLP-2 & Multiple myeloma & & - & - & - & - & - & - \\
\hline MOLP-8 & Multiple myeloma & & - & - & - & - & - & - \\
\hline MOLT-13 & T cell leukemia & - & - & - & - & - & - & - \\
\hline MOLT-14 & T cell leukemia & - & - & - & - & - & - & - \\
\hline MOLT-16 & $\mathrm{T}$ cell leukemia & - & - & - & - & - & - & - \\
\hline MOLT-17 & $\mathrm{T}$ cell leukemia & - & - & - & - & - & - & - \\
\hline MOLT-3 & T cell leukemia & - & - & - & - & - & - & - \\
\hline MOLT-4 & $\mathrm{T}$ cell leukemia & - & - & - & - & - & - & - \\
\hline MONO-MAC-1 & Acute monocytic Leukemia & - & - & - & - & - & - & - \\
\hline MONO-MAC-6 & Acute monocytic leukemia & - & - & - & - & - & - & - \\
\hline MOTN-1 & T cell leukemia & & - & - & - & - & - & - \\
\hline MSTO-211H & Lung carcinoma & - & - & - & - & - & - & - \\
\hline MT-3 & Breast carcinoma & - & - & - & - & - & - & - \\
\hline MUTZ-2 & Acute myeloid leukemia & - & - & - & - & - & - & - \\
\hline MUTZ-3 & Acute myelomonocytic leukemia & - & - & - & - & - & - & - \\
\hline MUTZ-5 & B cell precursor leukemia & - & - & - & - & - & - & - \\
\hline MV4-11 & Acute monocytic leukemia & - & - & - & - & - & - & - \\
\hline NALM-1 & Chronic myeloid leukemia in blast crisis & - & - & - & - & - & - & - \\
\hline NALM-19 & B cell precursor leukemia & & - & - & - & - & - & - \\
\hline NALM-6 & B cell precursor leukemia & - & - & - & - & - & - & - \\
\hline NAMALWA & Burkitt lymphoma & - & - & + & - & - & - & + \\
\hline NAMALWA.CSN/70 & Burkitt lymphoma & - & - & + & - & - & - & + \\
\hline NAMALWA.IPN/45 & Burkitt lymphoma & - & - & + & - & - & - & + \\
\hline NAMALWA.KN2 & Burkitt lymphoma & - & - & + & - & - & - & + \\
\hline NAMALWA.PNT & Burkitt lymphoma & - & - & + & - & - & - & + \\
\hline NB-4 & Acute promyelocytic leukemia & - & - & - & - & - & - & - \\
\hline NCI-H510A & Small cell extra-pulmonary carcinoma & & - & - & - & - & - & - \\
\hline NCI-H82 & Small cell lung carcinoma & & - & - & - & - & - & - \\
\hline
\end{tabular}


Table 3: Continued.

\begin{tabular}{|c|c|c|c|c|c|c|c|c|}
\hline Cell line & Zelltyp & RT-ELISA & $\mathrm{HCV}$ & EBV & $\mathrm{HBV}$ & HIV & HTLV & SMRV \\
\hline NCI-H929 & Multiple myeloma & - & - & - & - & - & - & - \\
\hline $\mathrm{NC}-\mathrm{NC}$ & B-lymphoblastoid cells & - & - & + & - & - & - & - \\
\hline NK-92 & Natural killer cell lymphoma & & - & + & - & - & - & - \\
\hline NOMO-1 & Acute myeloid leukemia & & - & - & - & - & - & - \\
\hline NTERA-2 & human embryonal carcinoma (teratocarcinoma) & & - & - & - & - & - & - \\
\hline NU-DHL-1 & B cell lymphoma & & - & - & - & - & - & - \\
\hline NU-DUL-1 & B cell lymphoma & & - & - & - & - & - & - \\
\hline OCI-AML2 & Acute myeloid leukemia & - & - & - & - & - & - & - \\
\hline OCI-AML3 & Acute myeloid leukemia & & - & - & - & - & - & - \\
\hline OCI-AML5 & Acute myeloid leukemia & - & - & - & - & - & - & - \\
\hline OCI-LY-19 & B cell lymphoma & & - & + & - & - & - & - \\
\hline OCI-M1 & Acute myeloid leukemia & & - & - & - & - & - & - \\
\hline OCI-M2 & Acute myeloid leukemia & & - & - & - & - & - & \\
\hline ONCO-DG-1 & Papillary thyroid carcinoma & & - & - & - & - & - & - \\
\hline OPM-2 & Multiple myeloma & - & - & - & - & - & - & - \\
\hline P12-ICHIKAWA & $\mathrm{T}$ cell leukemia & - & - & - & - & - & - & - \\
\hline PA-TU-8902 & Pancreas adenocarcinoma & - & - & - & - & - & - & - \\
\hline PA-TU-8988S & Pancreas adenocarcinoma & - & - & - & - & - & - & - \\
\hline PA-TU-8988T & Pancreas adenocarcinoma & - & - & - & - & - & - & - \\
\hline PC-3 & Prostate carcinoma & & - & - & - & - & - & - \\
\hline PEER & $\mathrm{T}$ cell leukemia & - & - & - & - & - & - & - \\
\hline PF-382 & $\mathrm{T}$ cell leukemia & - & - & - & - & - & - & - \\
\hline PL-21 & Acute myeloid leukemia & & - & - & - & - & - & - \\
\hline PLB-985 & Acute myeloid leukemia & - & - & - & - & - & - & - \\
\hline RAJI & Burkitt lymphoma & - & - & + & - & - & - & - \\
\hline RAMOS & Burkitt lymphoma & & - & - & - & - & - & - \\
\hline $\mathrm{RCH}-\mathrm{ACV}$ & B cell precursor leukemia & & - & - & - & - & - & - \\
\hline $\mathrm{RC}-\mathrm{K} 8$ & B cell lymphoma & & - & - & - & - & - & - \\
\hline RD-ES & Ewing's osteosarcoma & - & - & - & - & - & - & - \\
\hline REC-1 & B cell lymphoma & & - & - & - & - & - & - \\
\hline REH & Pre B cell leukemia & - & - & - & - & - & - & - \\
\hline RH-1 & Rhabdomyosarcoma & & - & - & - & - & - & - \\
\hline RH-18 & Rhabdomyosarcoma & & - & - & - & - & - & - \\
\hline RH-30 & Rhabdomyosarcoma & & - & - & - & - & - & - \\
\hline RH-41 & Rhabdomyosarcoma & & - & - & - & - & - & - \\
\hline RI-1 & B cell lymphoma & & - & - & - & - & - & - \\
\hline RL & B cell lymphoma & & - & - & - & - & - & - \\
\hline $\mathrm{RO}$ & B lymphoblastoid cell line & & - & + & - & - & - & - \\
\hline ROS-50 & B cell leukemia & & - & - & - & - & - & \\
\hline RPMI-2650 & Nasal septum squamous carcinoma & - & - & - & - & - & - & - \\
\hline RPMI-7951 & Melanoma & - & - & - & - & - & - & - \\
\hline RPMI-8226 & Multiple myeloma & - & - & - & - & - & - & - \\
\hline RPMI-8402 & $\mathrm{T}$ cell acute lymphoblastic leukemia & - & - & - & - & - & - & - \\
\hline RS4;11 & B cell precursor leukemia & & - & - & - & - & - & - \\
\hline RS-5 & Sacromatoid mesothelioma & & - & - & - & - & - & - \\
\hline RT-112 & Urinary bladder carcinoma & - & - & - & - & - & - & - \\
\hline RT-4 & Urinary bladder carcinoma & - & - & - & - & - & - & - \\
\hline RVH-421 & Melanoma & - & - & - & - & - & - & - \\
\hline S-117 & Thyroid sarcoma & - & - & - & - & - & - & - \\
\hline SAOS-2 & Osteogenic carcinoma & - & - & - & - & - & - & - \\
\hline SBC-2 & Cervix carcinoma (subclone of HELA) & - & - & - & - & - & - & - \\
\hline SBC-7 & Cervix carcinoma (subclone of HELA) & - & - & - & - & - & - & - \\
\hline SC-1 & B cell lymphoma & & - & - & - & - & - & - \\
\hline SCC-25 & Squamous cell carcinoma & & - & - & - & - & - & \\
\hline SCC-4 & Squamous cell carcinoma & & - & - & - & - & - & \\
\hline
\end{tabular}


Table 3: Continued.

\begin{tabular}{|c|c|c|c|c|c|c|c|c|}
\hline Cell line & Zelltyp & RT-ELISA & $\mathrm{HCV}$ & EBV & HBV & HIV & HTLV & SMRV \\
\hline SCLC-21H & Small cell lung carcinoma & - & - & - & - & - & - & - \\
\hline SCLC- $22 \mathrm{H}$ & Small cell lung carcinoma & - & - & - & - & - & - & - \\
\hline SD-1 & B lymphoblastoid cells & - & - & + & - & - & - & - \\
\hline SEM & B cell precursor leukemia & & - & - & - & - & - & - \\
\hline SET-2 & Essential thromobocythemia & & - & - & - & - & - & - \\
\hline $\mathrm{SH}-2$ & Acute myeloid leukemia & & - & - & - & - & - & - \\
\hline SHI-1 & Acute myeloid leukemia & & - & - & - & - & - & - \\
\hline SH-SY5Y & Neuroblastoma & - & - & - & - & - & - & - \\
\hline SIG-M5 & Acute monocytic leukemia & & - & - & - & - & - & - \\
\hline SIMA & Neuroblastoma & - & - & - & - & - & - & - \\
\hline SISO & Cervix carcinoma & - & - & - & - & - & - & - \\
\hline SK-ES-1 & Ewing's sarcoma & & - & - & - & - & - & - \\
\hline SK-HEP-1 & Liver adenocarcinoma & - & - & - & - & - & - & - \\
\hline SKM-1 & Acute myeloid leukemia & & - & - & - & - & - & - \\
\hline SK-MEL-1 & Melanoma & - & - & - & - & - & - & - \\
\hline SK-MEL-3 & Melanoma & - & - & - & - & - & - & - \\
\hline SK-MEL-30 & Melanoma & - & - & - & - & - & - & - \\
\hline SK-MES-1 & Squamous lung carcinoma & - & - & - & - & - & - & \\
\hline SK-MM-2 & Multiple Myeloma & - & - & - & - & - & - & - \\
\hline SK-N-BE(2) & Neuroblastoma & & - & - & - & - & - & - \\
\hline SK-N-MC & Neuroblastoma & - & - & - & - & - & - & - \\
\hline SKW-3 & $\mathrm{T}$ cell leukemia & - & - & - & - & - & - & \\
\hline SNB-19 & Glioblastoma & - & - & - & - & - & - & - \\
\hline SPI-801 & Chronic myeloid leukemia ( $\mathrm{K}-562$ subclone) & - & - & - & - & - & - & - \\
\hline SPI-802 & Chronic myeloid leukemia (K-562 subclone) & - & - & - & - & - & - & - \\
\hline SR-786 & Anaplastic large $\mathrm{T}$ cell lymphoma & - & - & - & - & - & - & - \\
\hline SU-DHL-1 & Anaplastic large cell lymphoma & - & - & - & - & - & - & - \\
\hline SU-DHL-10 & B cell lymphoma & & - & - & - & - & - & - \\
\hline SU-DHL-16 & B cell lymphoma & & - & - & - & - & - & - \\
\hline SU-DHL-4 & B cell lymphoma & & - & - & - & - & - & - \\
\hline SU-DHL-5 & B cell lymphoma & & - & - & - & - & - & - \\
\hline SU-DHL-6 & B cell lymphoma & & - & - & - & - & - & - \\
\hline SU-DHL-8 & B cell lymphoma & & - & - & - & - & - & - \\
\hline SUP-B15 & B cell precursor leukemia & - & - & - & - & - & - & - \\
\hline SUP-HD1 & Hodgkin lymphoma & & - & - & - & - & - & - \\
\hline SUP-M2 & Anaplastic large cell lymphoma & & - & - & - & - & - & - \\
\hline SUP-T1 & $\mathrm{T}$ cell lymphoma & - & - & - & - & - & - & - \\
\hline SUP-T11 & $\mathrm{T}$ cell leukemia & & - & - & - & - & - & - \\
\hline SW-1710 & Urinary bladder carcinoma & - & - & - & - & - & - & - \\
\hline SW-403 & Colon adenocarcinoma & - & - & - & - & - & - & - \\
\hline SW-480 & Colon adenocarcinoma & - & - & - & - & - & - & - \\
\hline SW-948 & Colon adenocarcinoma & - & - & - & - & - & - & - \\
\hline $\mathrm{T} 2$ & Human-human somatic cell hybrid & & - & + & - & - & - & \\
\hline $\mathrm{T}-24$ & Bladder carcinoma & - & - & - & - & - & - & - \\
\hline TALL-1 & T cell leukemia & & - & - & - & - & - & - \\
\hline TANOUE & B cell precursor leukemia & - & - & - & - & - & - & - \\
\hline TC-71 & Ewing's sarcoma & & - & - & - & - & - & - \\
\hline TCC-SUP & Bladder carcinoma & - & - & - & - & - & - & - \\
\hline TE-671 & Rhabdomyosarcoma & - & - & - & - & - & - & - \\
\hline TF-1 & Erythroleukemia & - & - & - & - & - & - & - \\
\hline TFK-1 & Bile duct carcinoma & - & - & - & - & - & - & - \\
\hline THP-1 & Acute monocytic leukemia & - & - & - & - & - & - & - \\
\hline TMM & Chronic myeloid leukemia & - & - & + & - & - & - & - \\
\hline TOM-1 & B cell precursor leukemia & & - & - & - & - & - & - \\
\hline TT2609-C02 & Follicular thyroid carcinoma & & - & - & - & - & - & \\
\hline
\end{tabular}


Table 3: Continued.

\begin{tabular}{|c|c|c|c|c|c|c|c|c|}
\hline Cell line & Zelltyp & RT-ELISA & $\mathrm{HCV}$ & EBV & HBV & HIV & HTLV & SMRV \\
\hline U-138-MG & Glioblastoma & - & - & - & - & - & - & - \\
\hline $\mathrm{U}-2197$ & Malignant fibrous histiosarcoma & - & - & - & - & - & - & - \\
\hline U-266 & Myeloma & - & - & - & - & - & - & - \\
\hline U-2932 & B cell lymphoma & & - & - & - & - & - & - \\
\hline U-2940 & B cell lymphoma & & - & - & - & - & - & - \\
\hline U-2973 & B cell lymphoma & & - & - & - & - & - & - \\
\hline U-698-M & B cell lymphoma & - & - & - & - & - & - & - \\
\hline U-937 & Hystiocytic lymphoma & - & - & - & - & - & - & - \\
\hline U-H01 & Hodgkin lymphoma & & - & - & - & - & - & - \\
\hline ULA & B cell lymphoma & & - & - & - & - & - & - \\
\hline UT-7 & Acute myeloid leukemia & - & - & - & - & - & - & - \\
\hline VA-ES-BJ & Epithelioid sarcoma & - & - & - & - & - & - & - \\
\hline VAL & B cell 1 & & - & + & - & - & - & - \\
\hline VM-CUB1 & Bladder carcinoma & - & - & - & - & - & - & - \\
\hline WERI-RB-1 & Retinoblastoma & - & - & - & - & - & - & - \\
\hline WSU-DLCL2 & B cell lymphoma & & - & - & - & - & - & - \\
\hline WSU-FSCCL & B cell lymphoma & & - & - & - & - & - & - \\
\hline WSU-NHL & B cell lymphoma & - & - & - & - & - & - & - \\
\hline Y-79 & Retinoblastoma & - & - & - & - & - & - & - \\
\hline YAPC & Pancreatic carcinoma & - & - & - & - & - & - & - \\
\hline YT & $\mathrm{T}$ cell/natural killer cell leukemia & - & - & + & - & - & - & - \\
\hline B95-8* & Lymphocytes & - & - & + & - & - & - & - \\
\hline $\operatorname{COS}-1^{*}$ & Kidney & - & - & - & - & - & - & - \\
\hline $\cos -7^{*}$ & Kidney & - & - & - & - & - & - & - \\
\hline VERO-B4* & Kidney & - & - & - & - & - & - & - \\
\hline
\end{tabular}

${ }^{*}$ : Monkey cell lines; -: negative; + (bold): positive.

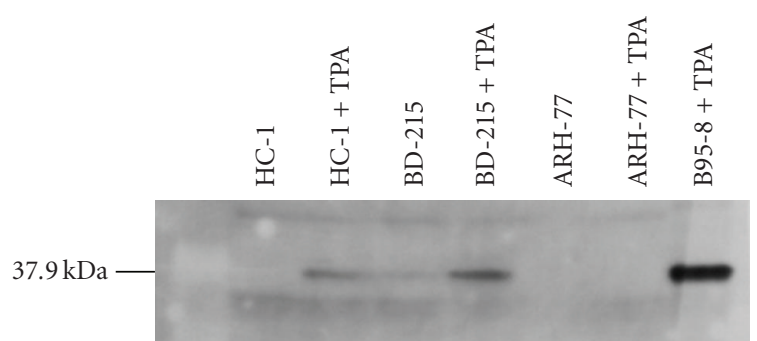

FIGURE 2: Detection of ZEBRA protein in $\mathrm{EBV}^{+}$cell lines. Western blot analysis with antibodies raised against ZEBRA shows that ZEBRA can be induced in the cell line HC-1 and that the cell line BD-215 can be stimulated to increase the expression of the immediate early protein. Expression in ARH-77 could not be induced by TPA during 72 hours. TPA-stimulated B95-8 was used as control for the expression of ZEBRA.

by interphase FISH. The analysis showed that the viral load of the nonproducing cells within a culture was heterogeneous. Some cells had high EBV loads, whereas other cells of the same cell culture showed low or even no viral load. For example, the cell line DOHH-2 contains only a few cells with several EBV episomes, whereas in most of the cells EBV DNA was completely absent (Figure 4(b)). Any crosscontamination of the cell line was excluded by DNA typing (data not shown). The heterogeneity of EBV load within a cell culture population and the finding that only a small fraction of cells can be stimulated to enter the lytic phase implies that specific cellular factors regulate the propagation of episomes in the nuclei and the permissivity of the cells related to EBV. Phosphorylation or methylation of EBV specific proteins or epigenetic events like DNA methylation or histone deacetylation might contribute to the cell specific regulation [39].

Linear EBV DNA was detected in a number of cell lines (Table 2). The expression of linear EBV genome DNA did not correspond to the expression of BZLF1 protein. Although all BZLF1 positive cell lines produced high levels of linear EBV DNA, many more BZLF1 negative cell lines also expressed significant levels of linear EBV genomes. This indicates that the lytic status of the EBV infection is not essential for the production of linear EBV genomes. The intensities of the linear EBV DNA bands did not correlate to the intensities of the episomes. For example, the cell line IM-9 displayed a very strong episomal DNA signal, whereas no linear DNA was detectable in untreated cells and very low amounts were seen in TPA/Na-butyrate treated cells (Figure 5). On the other hand, cell line YT showed a strong band for linear DNA, but a weak band for the episomal DNA. The number of episomes per cell was not affected by the stimulation with TPA/Na-butyrate, whereas the amount of linear DNA increased with the addition of TPA in those cell lines which can be stimulated with the phorbol ester. 


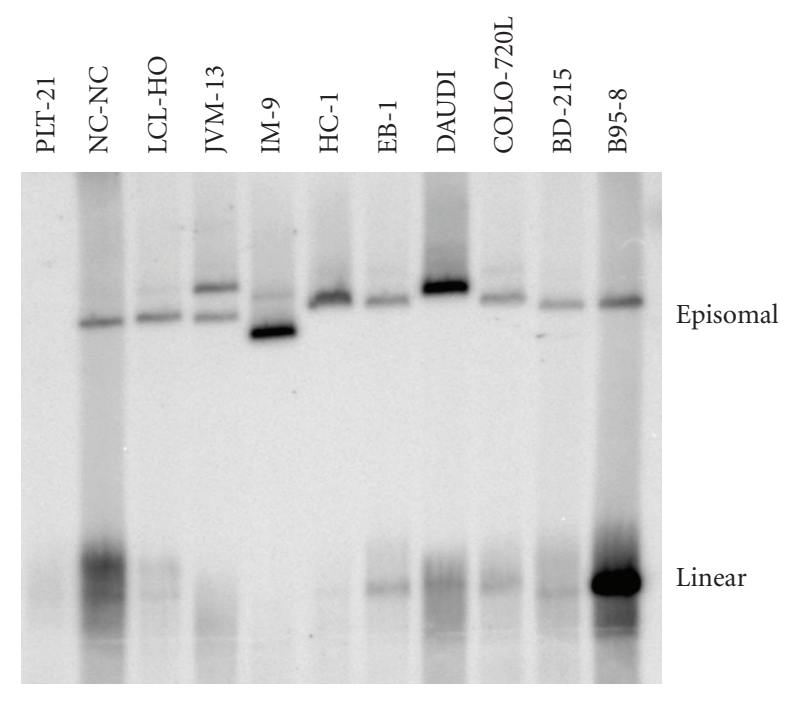

FIGURE 3: Detection of circular and linear EBV DNA in cell lines by in situ lysing gel analysis. $10^{6}$ cells were resuspended in a loading buffer containing RNase A and loaded into a well of a $0.8 \%$ agarose-TBE lysing gel containing SDS and proteinase $\mathrm{K}$. After electrophoresis the separated DNA was blotted onto nylon filters and the DNA was hybridized with ${ }^{32} \mathrm{P}$ labeled EBV cosmid cM-SalI-A. The upper bands on the autoradiograph constitute the episomal DNA, whereas the lower bands constitute the linear EBVDNA which is packed into the active viruses during virus formation. EBV genoms integrated into the chromosomes of the cells do not enter the gel. Controls include B95-8 as EBV-positive and PLT-21 as EBV-negative cell lines. Episomal EBV DNA can be detected in all EBV positive cell lines. The amount of linear EBV-DNA is highly diverse or not present (IM-9, JVM-13) and does not correlate with the amount of episomal DNA.

Cross-contamination is a serious problem in cell culture and causes mycoplasma infection and cell line crosscontamination. To find out whether a transfer of EBV from one cell culture to another can be demonstrated, we investigated the clonality of the EBV genomes. We performed Southern blot analysis with genomic DNA of the EBVPCR positive cell lines digested with the restriction enzyme XhoI. Applying EBV cosmids covering almost the whole EBV genome [15] each cell line displayed a unique EBV genotype. The most striking differences occurred in the lengths of the terminal repeat (TR) regions which reflect the numbers of repetitive exons. The other parts of the genome covered by the cosmids (ca. 83\% of the B95-8 EBV sequence) showed also a high variability. Several different patterns can be identified per cosmid probe and the combination of several cosmid probes revealed a high number of different genotypes (Figure 6). Even the cell lines which were described to be established with EBV particles of the B95-8 cell line displayed differences in the lenght of the TR regions of the EBV genotypes. The JVM cell lines were all established using EBV and TPA [32]. Nevertheless, the cell lines display different patterns concerning the TR region and a few additional bands within the EBV genome. The EHEB cell line was also described to be transformed by B95-8 EBV viruses [9]. The EHEB cell line displays distinct bands in the XhoI-digested

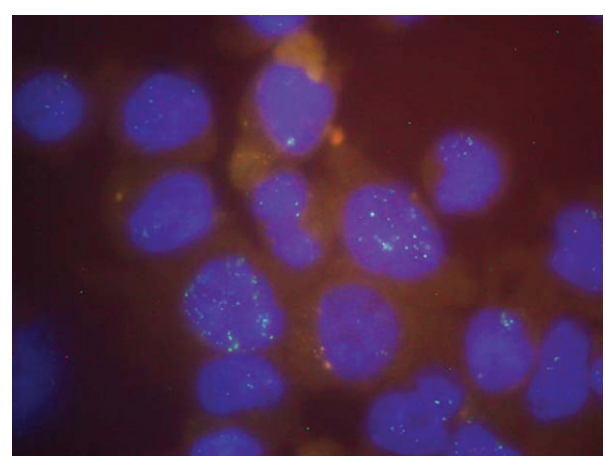

(a)

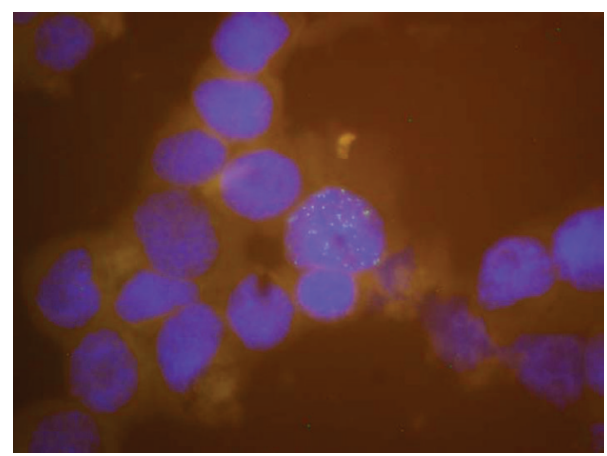

(b)

FIgURE 4: Interphase FISH assay for the demonstration of EBV in cell lines. Hybridization was performed with EBV cosmid cMSalI-A labeled with Spectrum Green by nick-translation. Nuclei were stained with DAPI. (a) Nuclei of cell line BONNA-12 contains heterogeneous numbers of EBV copies. (b) Cell line DOHH-2 displays only few cells contaminated with EBV.

EBV DNA different from those found in the JVM cell lines. Nevertheless, the bands of the B95-8 EBV-transformed cell lines detected in the Southern blots are all more or less prominently represented within the pattern of the B95-8 cell line. From these results, we conclude that the B95-8 cell line harbors different genotypes of EBV with the ability to transform other cells.

Taken together, the various patterns of digested EBV indicate that the infections with $\mathrm{EB}$ viruses originated from the patient or from the transforming viruses, but not from dissemination during cell culturing. Although mycoplasma and cross contaminants are mainly introduced into cell cultures by inadequate cell culture techniques, this does not seem to be the case with regard to the distribution of EBV in cell cultures. The low number of unintended intercell line contamination by EBV might be based on the low number of cell lines which produce actively EBV. Additionally, only a limited number of cell lines are susceptible to the infection with EBV at all.

3.2. Detection of $H B V$. HBV particles contain a circular, partially double-stranded DNA of $3.2 \mathrm{~kb}$. HBV can be grown in primary cell cultures of normal adult or fetal human hepatocytes, but propagation was not yet shown in untreated 


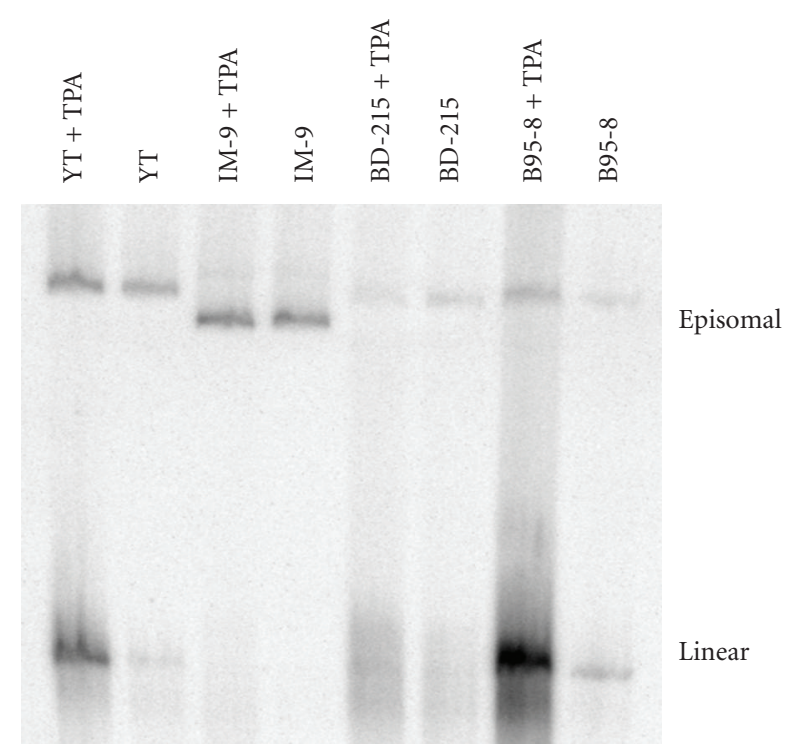

FIgURE 5: Detection of circular and linear EBV DNA in untreated and TPA-treated cell lines by in situ lysing gel analysis. Cells were stimulated for 72 hours with $10^{-7} \mathrm{M}$ TPA and $0.3 \mathrm{M}$ Na-butyrate. All conditions were as described in the legend for Figure 3. The cell lines B95-8 and YT can be efficiently stimulated to produce high amounts of linear EBV genomes, whereas BD-215 cannot be triggered to produce more linear DNA and IM-9 is not induced to produce linear DNA by TPA/Na-butyrate.

continuous cell lines. Production of HBV particles can be achieved to date only by transfection of hepatocyte cell lines with plasmids containing HBV genomes [47]. In cell lines, the HBV genome is integrated into the eukaryotic chromosomes with variable copy numbers as shown for several cell lines, for example, HCCM, HEP-3B, HUH-1, HUH-4, and PLC/PRF/5 [48]. Except for HCCM, all these cell lines express the hepatitis B surface antigen HBsAg.

The HBV PCR assay used here amplified conserved sequences of the core region of $\mathrm{HBV}$ and was evaluated using HBV reference plasma No 1 (subtype ad) and No 2 (subtype ay) which were established in cooperation with the European Study Group on Viral Hepatitis (EUROHEP). In order to determine the detection limit, we performed a dilution series of the HBV particles in conditioned cell culture supernatant of an HBV negative cell line. Subsequently, the HBV particles were recollected by ultracentrifugation, DNA was extracted, and the PCR reaction was performed as described in the methods section. The sensitivity was determined as ca. 50 particles per PCR reaction. This corresponds to ca. $250 \mathrm{HBV}$ particles per $\mathrm{mL}$ cell culture supernatant (data not shown).

We screened 465 primate cell lines (Table 3 ) by performing PCR assays for the detection of active HBV with DNA extractions of the cell culture supernatants and found no $\mathrm{HBV}^{+}$cell lines. The HEP-3B cell line was described to carry the HBV genome integrated into the eukaryotic chromosomes [49], but the PCR method we applied detected the contamination neither in the supernatant nor using genomic DNA of the cell line. Su et al. [49] investigated the HBV genome and the integration site within the eukaryotic

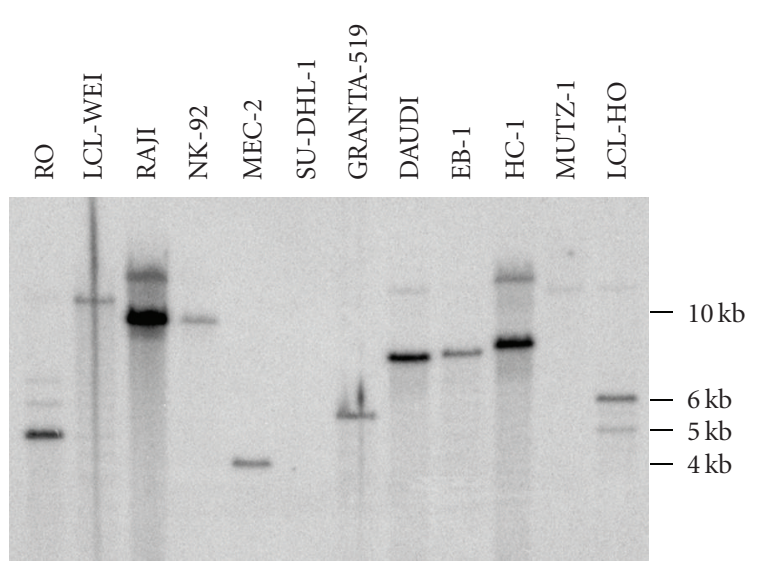

FIGURE 6: Southern blot analysis of different cell lines. Fifteen $\mu \mathrm{g}$ genomic DNA of the cell lines were digested with XhoI and the restriction fragments were separated on an agarose gel. The DNA was blotted onto nylon filters and the blot was hybridized to a ca. $900 \mathrm{bp}{ }^{32} \mathrm{P}$-labeled PCR product spanning the $5^{\prime}$-region of EBV (LMP fragment 1). A rehybridization of the same blot with a probe for the 3 -region of the linear EBV genome after stripping revealed the same bands, indicating that circular EBV DNA is detected.

genome. They determined a ca. $2.3 \mathrm{~kb}$ fragment originating from $\mathrm{HBV}$ in the HEP-3B cell line and the integration was associated with a chromosomal translocation of the chromosomes 4 and 13. The HBV core region is deleted in the HEP-3B cell line and was thus not detected by the PCR analysis. We confirmed the presence of the HBV fragment in the HEP-3B cell line by Southern blot analysis (Figure 7) on genomic DNA and by PCR amplification of the coding region of the HBsAg.

In HEP-G2 and SK-HEP-1, a hepatocellular carcinoma, and a liver adenocarcinoma cell line, respectively, we did not detect HBV sequences by PCR or Southern blot analysis. Both cell lines are not contaminated with HBV.

3.3. Detection of HCV. HCV infections are widely distributed all over the world and are associated with chronic hepatitis. Until its identification in 1988, the virus was the predominant causative of transfusion-associated hepatitis. Similarly to HBV, until now HCV cannot be propagated in unmanipulated continuous human cell lines.

$\mathrm{HCV}$ is a $9.6 \mathrm{~kb}$ linear positive-stranded RNA virus and can be detected by reverse transcriptase PCR (RT-PCR). The $5^{\prime}$-UTR is the most conserved part of the virus genome and commonly used for the amplification by RT-PCR. We extracted total RNA from the cell lines and the integrity of the RNA was evaluated by demonstration of the rRNA bands on an ethidium bromide stained gel. The subsequent RT reaction was verified by a PCR reaction amplifying the ubiquitously expressed $A B L$ transcript. This PCR allows (i) to demonstrate the sensitivity of the RT-PCR, because $A B L$ is only moderately transcribed in human cells, and (ii) to distinguish between the cDNA and residual genomic DNA, because the primers are located in two different exons of the $A B L$ gene. Due to the lack of availability of $\mathrm{HCV}$ positive 


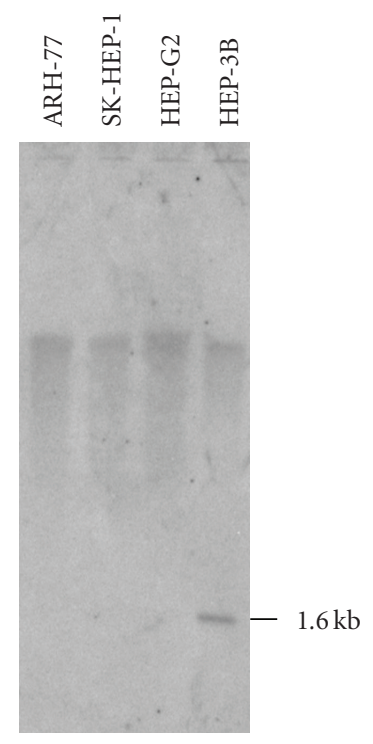

FIGURE 7: Southern blot analysis for the detection of HBV sequences in human cell lines. The cell lines HEP-3B, HEP-G2, and SK-HEP1 are cell lines established from human hepatocellular carcinomas. The ARH-77 is a human hematopoietic cell line and serves as a negative control. Genomic DNA was digested with BamHI, separated on an agarose gel, blotted and hybridized with a ${ }^{32} \mathrm{P}$ labeled PCR fragment covering the Hepatitis B surface antigen coding region. The hepatocellular carcinoma cell lines SK-HEP-1 and HEP-G2 display no HBV sequences, whereas HEP-3B shows a hybridization signal at about $1.6 \mathrm{~kb}$ originating from $\mathrm{HBV}$ sequences integrated into the cellular genome.

cell lines, we used a plasmid containing the $5^{\prime}$-UTR of HCV as positive control and produced an internal control DNA to verify each PCR reaction. The sensitivity of the assay was determined as 10-100 copies per PCR reaction.

We investigated 465 cell lines (Table 3 ) applying RT-PCR for the conserved $5^{\prime}$-UTR of the HCV genome. None of the cell lines were positive for HCV. This result supports the observation that HCV cannot be propagated in human or other primate cell lines.

3.4. Detection of HIV-1 and HTLV-I and -II. The retroviruses HIV-1 and HTLV-I and II infect human T cells and are involved in the development of AIDS and the adult T-cell leukemia, respectively. The retroviruses contain two RNA molecules which are reverse transcribed into DNA and integrated as proviruses into the host genome. HIV and HTLV can be propagated in continuous cell lines and a number of cell lines were described as being latently infected or actively producing viruses.

PCR assays were established to detect latent infections in terms of proviruses of HIV-1 and HTLV-I and -II in the cell lines. The sensitivity of the PCR assays was determined as about 20 copies per reaction. DNA of the MT- 1 cell line was used as positive control for the HTLV-PCR and a plasmid containing the HIV-1 gag and pol regions as positive control for HIV-1.
In total 465 primate cell lines of the cell bank (Table 3) were analyzed by PCR for the presence of those retroviruses and none of the cell lines were found to be infected with HIV or HTLV sequences. Furthermore, 293 of these cell lines were tested for the activity of RT. Only the cell line KASUMI-1 was found to be positive. The activity of $5 \mathrm{~mL}$ conditioned KASUMI-1 cell culture supernatant showed an RT activity that was equivalent to approximately $2 \mathrm{ng}$ of HIV-1 RT (specific activity $>5 \mathrm{U} / \mu \mathrm{g}$ ). For comparison, $5 \mathrm{~mL}$ supernatant of the ovine cell line FLK-BLV, which is infected with the bovine leukemia virus, shows an activity equivalent to ca. $10 \mathrm{ng}$ of HIV-1 RT. The cause of the RT activity could not be determined. But PCR analyses excluded the presence of HIV-1, HTLV-I/-II, and SMRV.

3.5. Detection of SMRV. SMRV was first isolated from the lung cell culture of a squirrel monkey after cocultivation with other cell cultures [50]. The endogenous virus belongs to the beta-retroviruses and exhibits Mg-dependent RT. SMRV is not pathogenic to its natural host and pathogenicity was not described for human or other species. The xenotropic virus was shown to be expressed in different cell lines of canine, man, chimpanze, rhesus monkey, and mink origin. Natural or alternate hosts other than squirrel monkey were not yet identified.

Already in 1974 retroviral particles were detected in the human hematopoietic cell line RPMI-8226 which were later identified as SMRV $[6,51]$. Oda et al. reported the detection of retroviruses in the human lymphoblastoid cell line HLB which turned out to be $\operatorname{SMRV}[52,53]$. Middleton et al. reported the insertion of SMRV sequences in the genome of the human Burkitt lymphoma cell line Namalwa [54]. The subclone Namalwa.IPN/45 contains two partial SMRV copies integrated into the cMYC gene locus and 10 further copies integrated at different sites of the genome of the cell line. They also found SMRV sequences in the EBV producing monkey cell line B95-8 and demonstrated that SMRV was transmitted when EBV particles from the B958 cell line were used to establish a B lymphoblastoid cell line. SMRV sequences were also detected in interferon- $\alpha$ preparations which were produced using the Namalwa cell line [55]. Retroviruses generally insert themselves into the genome of the host cell. As seen in the cell line Namalwa, the insertion can affect not only the transcription activity of cellular oncogenes but also tumor suppressor genes or other regulatory genes. Beside the possibility of altering the cellular characteristics, this leads also to a certain, at least theoretically, possible pathogenicity of retrovirus infections per se; hence the release of those viruses-especially with a very broad host cell spectrum such as xenotropic SMRVshould be minimized. Moreover, a potential risk occurs when cells infected with retroviruses are subjected to retroviralmediated gene transfer. A recombination of the replication deficient retrovirus and the wild type retroviral genetic information might lead to a complementation of the replication defect and to replication-competent retroviruses [56].

We investigated 430 human and 4 monkey cell lines (Table 3) for the occurrence of SMRV DNA sequences in the 
genome. Six cell lines were found to be positive for SMRV: five Namalwa subclones (Namalwa, Namalwa.CSN/70, Namalwa.IPN/45, Namalwa.KN2, Namalwa.PNT) and the human lymphoblastoid cell line LCL-HO. Middleton et al. investigated Namalwa cell lines from different laboratories and found no SMRV-free Nalmalwa cell cultures [54]. Our subclones were received from two different laboratories in Japan and Scotland. Presumably, all NAMALWA cell lines are contaminated with SMRV and no SMRV-free cell line is available. The LCL-HO cell line is a lymphoblastoid cell line which was established by transformation of a patients primary B cells with EBV. We suspect that SMRV was transmitted by the use of EBV from an SMRV infected B95-8 cell line. Other LCLs which were transformed with EBV from B95-8 showed no SMRV contamination. This indicates that only some of the B95-8 subclones contain SMRV.

The cell lines were received from different sources worldwide. The low infection rate of the cell lines indicates that SMRV is not transmitted to other cell cultures comparable to the distribution of mycoplasma or cell line cross contaminations, although many different cell types were shown to be susceptible to an infection. Nevertheless, the transmission of these xenotropic viruses during cultivation and handling of infected cell cultures to other cell lines cannot be excluded.

\section{Conclusions}

In summary, we showed that human and other primate cell lines directly obtained from a biological resource center do not carry high-risk viral contaminants and thus do not represent safety risks for cell culturists. The PCR assays provide a robust, fast, inexpensive, sensitive, and reliable method for routine screening. The additional feature of incorporating an internal control in each assay reduces the possibility of false-negative data. Importantly, unlike mycoplasma and other bacterial infections and cell line cross contamination, viruses are not disseminated among cell lines due to poor cell culture technique. Only a minor part of the $\mathrm{EBV}^{+}$cell lines produces active viruses or can be stimulated to produce them. Detection of BZLF1 protein by Western blot, TR sequences by Southern blot, and interphase FISH can be applied to recognize cell lines producing active EBV particles and to assign a cell culture to a legal risk group. Newly established cell lines should be tested for EBV-infections to detect EBV-transformed Bcells giving rise to B-LCLs. On the other hand, the use of EBV from an SMRV ${ }^{+}$B95-8 cell line to establish B-LCLs might carry the risk of coinfecting the reccipient cells with SMRV.

\section{Acknowledgment}

The authors thank Dr. Roderick A.F. MacLeod and Maren Kaufmann for technical support on the FISH analyses and Anne Leena Koelz for performing SMRV assays on nonhuman primate cell lines.

\section{References}

[1] A. C. E. Moor, T. M. Dubbelman, J. VanSteveninck, and A. Brand, "Transfusion-transmitted diseases: risks, prevention and perspectives," European Journal of Haematology, vol. 62, no. 1, pp. 1-18, 1999.

[2] H. Zur Hausen, "Viruses in human cancers," European Journal of Cancer, vol. 35, no. 14, pp. 1878-1885, 1999.

[3] A. Farrugia, "Evolving perspectives in product safety for haemophilia," Haemophilia, vol. 8, no. 3, pp. 236-243, 2002.

[4] P. A. Lazo, "Structure, DNaseI hypersensitivity and expression of integrated papilloma virus in the genome of HeLa cells," European Journal of Biochemistry, vol. 165, no. 2, pp. 393-401, 1987.

[5] H. G. Drexler, C. C. Uphoff, W. G. Dirks, and R. A. F. MacLeod, "Mix-ups and mycoplasma: the enemies within," Leukemia Research, vol. 26, no. 4, pp. 329-333, 2002.

[6] M. Popovic, V. S. Kalyanaraman, M. S. Reitz, and M. G. Sarngadharan, "Identification of the RPMI 8226 retrovirus and its dissemination as a significant contaminant of some widely used human and marmoset cell lines," International Journal of Cancer, vol. 30, no. 1, pp. 93-99, 1982.

[7] M. Pienkowska and A. Seth, "Detection of squirrel monkey retroviral sequences in interferon samples," Journal of Hepatology, vol. 28, no. 3, pp. 396-403, 1998.

[8] E. Kieff and A. B. Rickinson, "Epstein-Barr virus and its replication," in Fields Virology, B. N. Fields, D. M. Knipe, and P. M. Howley, Eds., pp. 2603-2654, Lippincott-Williams and Wilkins, Philadelphia, Pa, USA, 5th edition, 2007.

[9] H. G. Drexler, W. Dirks, R. A. F. MacLeod, H. Quentmeier, K. G. Steube, and C. C. Uphoff, "DSMZ catalogue of human and animal cell lines," 2008, http://www.dsmz.de/human_and_ animal_cell_lines/cell_line_index.php.

[10] C. C. Uphoff and H. G. Drexler, "Comparative PCR analysis for detection of mycoplasma infections in continuous cell lines," In Vitro Cellular and Developmental Biology: Animal, vol. 38, no. 2, pp. 79-85, 2002.

[11] W. G. Dirks, S. Faehnrich, I. A. J. Estella, and H. G. Drexler, "Short tandem repeat DNA typing provides an international reference standard for authentication of human cell lines," Altex, vol. 22, no. 2, pp. 103-109, 2005.

[12] H. Quentmeier, W. G. Dirks, R. A. F. Macleod, J. Reinhardt, M. Zaborski, and H. G. Drexler, "Expression of HOX genes in acute leukemia cell lines with and without MLL translocations," Leukemia and Lymphoma, vol. 45, no. 3, pp. 567-574, 2004.

[13] J. Eberle and R. Seibl, "A new method for measuring reverse transcriptase activity by ELISA," Journal of Virological Methods, vol. 40, no. 3, pp. 347-356, 1992.

[14] T. Gardella, P. Medveczky, T. Sairenji, and C. Mulder, "Detection of circular and linear herpesvirus DNA molecules in mammalian cells by gel electrophoresis," Journal of Virology, vol. 50, no. 1, pp. 248-254, 1984.

[15] A. Polack, G. Hartl, and U. Zimber, "A complete set of overlapping cosmid clones of M-ABA virus derived from nasopharyngeal carcinoma and its similarity to other EpsteinBarr virus isolates," Gene, vol. 27, no. 3, pp. 279-288, 1984.

[16] C. C. Uphoff, Z.-B. Hu, S. M. Gignac, et al., "Characterization of the monocyte-specific esterase (MSE) gene," Leukemia, vol. 8, no. 9, pp. 1510-1526, 1994.

[17] D. E. Kellogg and S. Kwok, "Detection of human immunodeficiency virus," in PCR Protocols, M. A. Innis, D. H. Gelfand, J. J. Sninsky, and T. J. White, Eds., pp. 337-347, Academic Press, San Diego, Calif, USA, 1st edition, 1990. 
[18] S. Kwok, D. Kellogg, G. Ehrlich, B. Poiesz, S. Bhagavati, and J. J. Sninsky, "Characterization of a sequence of human T cell leukemia virus type I from a patient with chronic progressive myelopathy," Journal of Infectious Diseases, vol. 158, no. 6, pp. 1193-1197, 1988.

[19] I. Saito, B. Servenius, T. Compton, and R. I. Fox, "Detection of Epstein-Barr virus DNA by polymerase chain reaction in blood and tissue biopsies from patients with Sjogren's syndrome," Journal of Experimental Medicine, vol. 169, no. 6, pp. 2191-2198, 1989.

[20] C. C. Uphoff, A. Carbone, G. Gaidano, and H. G. Drexler, "HHV-8 infection is specific for cell lines derived from primary effusion (body cavity-based) lymphomas," Leukemia, vol. 12, no. 11, pp. 1806-1809, 1998.

[21] P. Pontisso, M. G. Ruvoletto, G. Fattovich, et al., "Clinical and virological profiles in patients with multiple hepatitis virus infections," Gastroenterology, vol. 105, no. 5, pp. 1529-1533, 1993.

[22] I. Miyoshi, I. Kubonishi, and S. Yoshimoto, “Type C virus particles in a cord T-cell line derived by co-cultivating normal human cord leukocytes and human leukaemic T cells," Nature, vol. 294, no. 5843, pp. 770-771, 1981.

[23] A. Telenti, P. Imboden, and D. Germann, "Competitive polymerase chain reaction using an internal standard: application to the quantitation of viral DNA," Journal of Virological Methods, vol. 39, no. 3, pp. 259-268, 1992.

[24] L. F. Lopes, M. M. Bacchi, D. Elgui-de-Oliveira, S. G. Zanati, M. Alvarenga, and C. E. Bacchi, "Epstein-Barr virus infection and gastric carcinoma in Sao Paulo State, Brazil," Brazilian Journal of Medical and Biological Research, vol. 37, no. 11, pp. 1707-1712, 2004.

[25] G. Ragona, I. Ernberg, and G. Klein, "Induction and biological characterization of the Epstein-Barr virus (EBV) carried by the Jijoye lymphoma line," Virology, vol. 101, no. 2, pp. 553-557, 1980.

[26] G. F. Bahr, U. Mikel, and G. Klein, "Localization and quantitation of EBV associated nuclear antigen (EBNA) in Raji cells," Beitrage zur Pathologie, vol. 155, no. 1, pp. 72-78, 1975.

[27] J. F. de Kroon, P. M. Kluin, H. C. Kluin-Nelemans, R. Willemze, and J. H. F. Falkenburg, "Homing and antigenic characterization of a human non-Hodgkin's lymphoma B cell line in severe combined immunodeficient (SCID) mice," Leukemia, vol. 8, no. 8, pp. 1385-1391, 1994.

[28] H. C. Kluin-Nelemans, J. Limpens, J. Meerabux, et al., "A new non-Hodgkin's B-cell line (DoHH2) with a chromosomal translocation $\mathrm{t}(14 ; 18)(\mathrm{q} 32 ; \mathrm{q} 21)$," Leukemia, vol. 5, no. 3, pp. 221-224, 1991.

[29] A. Carbone, A. M. Cilia, A. Gloghini, et al., "Establishment of HHV-8-positive and HHV-8-negative lymphoma cell lines from primary lymphomatous effusions," International Journal of Cancer, vol. 73, no. 4, pp. 562-569, 1997.

[30] A. Carbone, A. M. Cilia, A. Gloghini, et al., "Establishment and characterization of EBV-positive and EBV-negative primary effusion lymphoma cell lines harbouring human herpesvirus type-8," British Journal of Haematology, vol. 102, no. 4, pp. 1081-1089, 1998.

[31] J. H. Schiller, G. Bittner, L. F. Meisner, et al., "Establishment and characterization of an Epstein-Barr virus spontaneously transformed lymphocytic cell line derived from a hairy cell leukemia patient," Leukemia, vol. 5, no. 5, pp. 399-407, 1991.

[32] J. V. Melo, L. Foroni, V. Brito-Babapulle, L. Luzzatto, and D. Catovsky, "The establishment of cell lines from chronic B cell leukaemias: evidence of leukaemic origin by karyotypic abnormalities and Ig gene rearrangement," Clinical and Experimental Immunology, vol. 73, no. 1, pp. 23-28, 1988.

[33] D. Saltman, N. S. Bansal, F. M. Ross, J. A. Ross, G. Turner, and K. Guy, "Establishment of a karyotypically normal B-chronic lymphocytic leukemia cell line; evidence of leukemic origin by immunoglobulin gene rearrangement," Leukemia Research, vol. 14, no. 4, pp. 381-387, 1990.

[34] L. Falk, L. Wolfe, and F. Deinhardt, "Epstein Barr virus: transformation of non human primate lymphocytes in vitro," International Journal of Cancer, vol. 13, no. 3, pp. 363-376, 1974.

[35] T. M. McCarty, S. Rajaraman, F. F. B. Elder, P. Gadson, and E. B. Thompson, "Establishment and characterization of a human myeloid cell line from Philadelphia chromosomenegative myeloblastic leukemia arising in a patient with myelodysplastic syndrome," Blood, vol. 70, no. 5, pp. 16651672, 1987.

[36] K. H. Th'ng, G. Garewal, and L. Kearney, "Establishment and characterization of three new malignant lymphoid cell lines," International Journal of Cancer, vol. 39, no. 1, pp. 89-93, 1987.

[37] J.-H. Gong, G. Maki, and H.-G. Klingemann, "Characterization of a human cell line (NK-92) with phenotypical and functional characteristics of activated natural killer cells," Leukemia, vol. 8, no. 4, pp. 652-658, 1994.

[38] E. Grogan, H. Jenson, and J. Countryman, "Transfection of a rearranged viral DNA fragment, WZhet, stably converts latent Epstein-Barr viral infection to productive infection in lymphoid cells," Proceedings of the National Academy of Sciences of the United States of America, vol. 84, no. 5, pp. 13321336, 1987.

[39] G. Miller, A. El-Guindy, J. Countryman, J. Ye, and L. Gradoville, "Lytic cycle switches of oncogenic human gammaherpesviruses(1)," Advances in Cancer Research, vol. 97, pp. 81-109, 2007.

[40] L. Gradoville, D. Kwa, A. El-Guindy, and G. Miller, "Protein kinase C-independent activation of the Epstein-Barr virus lytic cycle," Journal of Virology, vol. 76, no. 11, pp. 5612-5626, 2002.

[41] P. M. Lieberman, J. M. Hardwick, J. Sample, G. S. Hayward, and S. D. Hayward, "The Zta transactivator involved in induction of lytic cycle gene expression in Epstein-Barr virusinfected lymphocytes binds to both AP-1 and ZRE sites in target promoter and enhancer regions," Journal of Virology, vol. 64, no. 3, pp. 1143-1155, 1990.

[42] P. Di Francesco, A. Lisi, S. Rieti, V. Manni, S. Grimaldi, and E. Garaci, "Cocaine potentiates the switch between latency and replication of Epstein-Barr virus in Raji cells," Biochemical and Biophysical Research Communications, vol. 264, no. 1, pp. 3336, 1999.

[43] S. Gargano, D. Caporossi, G. Gualandi, and E. Calef, "Different localization of Epstein-Barr virus genome in two subclones of the Burkitt lymphoma cell line Namalwa," Genes Chromosomes and Cancer, vol. 4, no. 3, pp. 205-210, 1992.

[44] J. Gao, X. Luo, K. Tang, X. Li, and G. Li, "Epstein-Barr virus integrates frequently into chromosome $4 \mathrm{q}, 2 \mathrm{q}, 1 \mathrm{q}$ and $7 \mathrm{q}$ of Burkitt's lymphoma cell line (Raji)," Journal of Virological Methods, vol. 136, no. 1-2, pp. 193-199, 2006.

[45] A. Henderson, S. Ripley, M. Heller, and E. Kieff, "Chromosome site for Epstein-Barr virus DNA in a Burkitt tumor cell line and in lymphocytes growth-transformed in vitro," Proceedings of the National Academy of Sciences of the United States of America, vol. 80, no. 7 I, pp. 1987-1991, 1983. 
[46] M. Nonoyama and J. S. Pagano, "Homology between Epstein Barr virus DNA and viral DNA from Burkitt's lymphoma and nasopharyngeal carcinoma determined by DNA DNA reassociation kinetics," Nature, vol. 242, no. 5392, pp. 44-47, 1973.

[47] M. A. Sells, M.-L. Chen, and G. Acs, "Production of hepatitis B virus particles in Hep G2 cells transfected with cloned hepatitis B virus DNA," Proceedings of the National Academy of Sciences of the United States of America, vol. 84, no. 4, pp. 1005-1009, 1987.

[48] N. Tay, S.-H. Chan, and E.-C. Ren, "Detection of integrated hepatitis B virus DNA in hepatocellular carcinoma cell lines by nonradioactive in situ hybridization," Journal of Medical Virology, vol. 30, no. 4, pp. 266-271, 1990.

[49] T. S. Su, W.-L. Hwang, and Y. K. Yauk, "Characterization of hepatitis B virus integrant that results in chromosomal rearrangement," DNA and Cell Biology, vol. 17, no. 5, pp. 415425, 1998 .

[50] R. L. Heberling, S. T. Barker, and S. S. Kalter, "Oncornavirus: isolation from a squirrel monkey (Saimiri sciureus) lung culture," Science, vol. 195, no. 4275, pp. 289-292, 1977.

[51] M. Popovic, J. Ponten, and M. Grofova, "Detection of oncornavirus like particles in human cell lines derived from tumors of hemopoietic tissue," Neoplasma, vol. 21, no. 6, pp. 619-627, 1974.

[52] T. Oda, S. Ikeda, S. Watanabe, M. Hatsushika, K. Akiyama, and F. Mitsunobu, "Molecular cloning, complete nucleotide sequence, and gene structure of the provirus genome of a retrovirus produced in a human lymphoblastoid cell line," Virology, vol. 167, no. 2, pp. 468-477, 1988.

[53] T. Oda, M. Hatsushika, S. Watanabe, et al., "Immunoelectron microscopic and immunoblotting analyses of a retrovirus produced in a human lymphoblastoid cell line with a monoclonal antibody," Cellular and Molecular Biology, vol. 32, no. 3, pp. 343-350, 1986.

[54] P. G. Middleton, S. Miller, J. A. Ross, C. M. Steel, and K. Guy, "Insertion of SMRV-H viral DNA at the c-myc gene locus of a BL cell line and presence in established cell lines," International Journal of Cancer, vol. 52, no. 3, pp. 451-454, 1992.

[55] M. Miyazawa, Y. Yanai, and M. Kurimoto, "Squirrel monkey retrovirus (SMRV) sequence from an SMRV- negative cell line?" Journal of Hepatology, vol. 31, no. 5, pp. 967-968, 1999.

[56] C. Voelkel, A. Lührmann, C. Baum, and H. E. von der Leyen, "Retrovirus mediated hematopoietic gene therapy: a European regulatory perspective with special focus on the situation in Germany," Cellular Therapy and Transplantation, vol. 1, no. 4, 2009. 

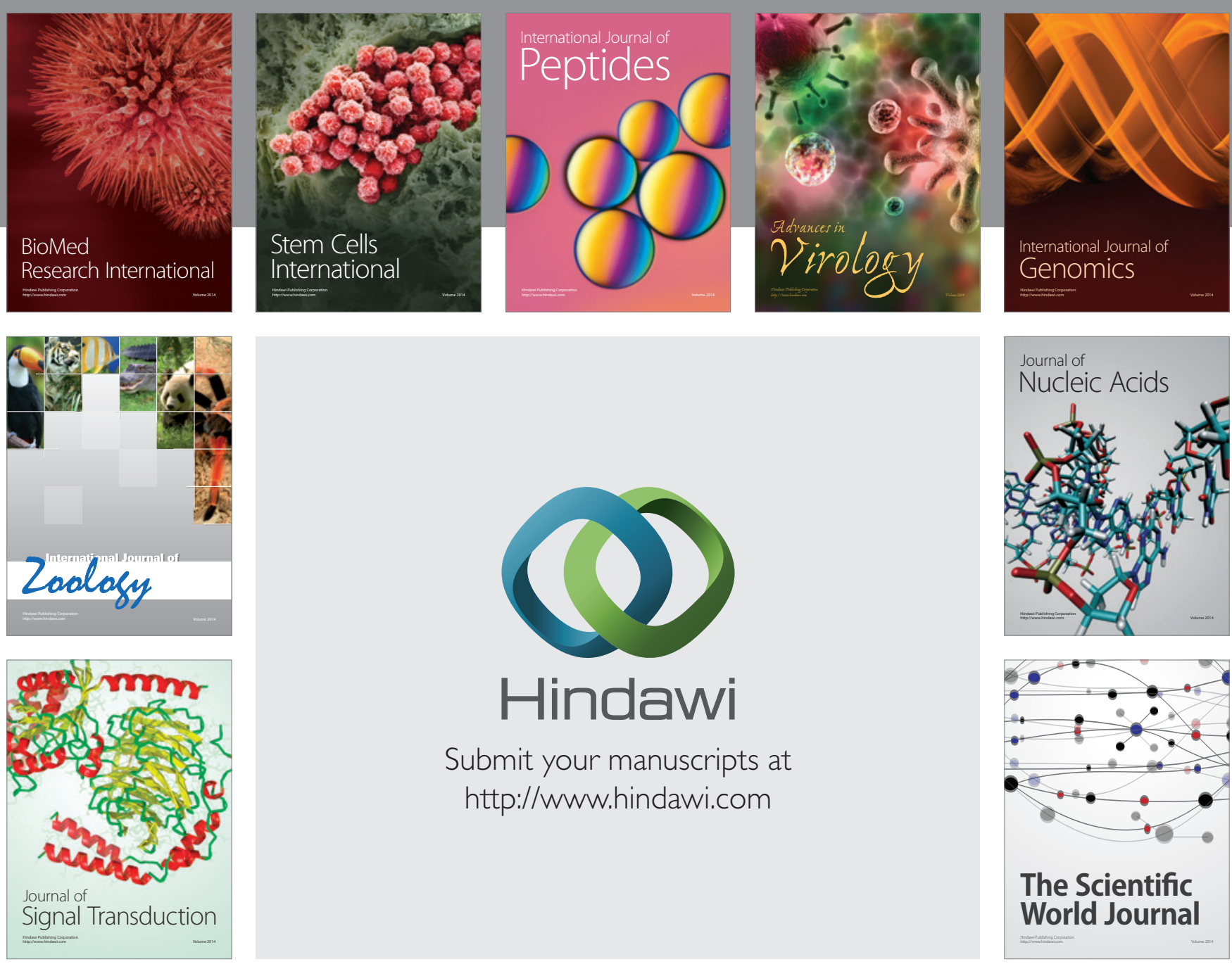

Submit your manuscripts at

http://www.hindawi.com
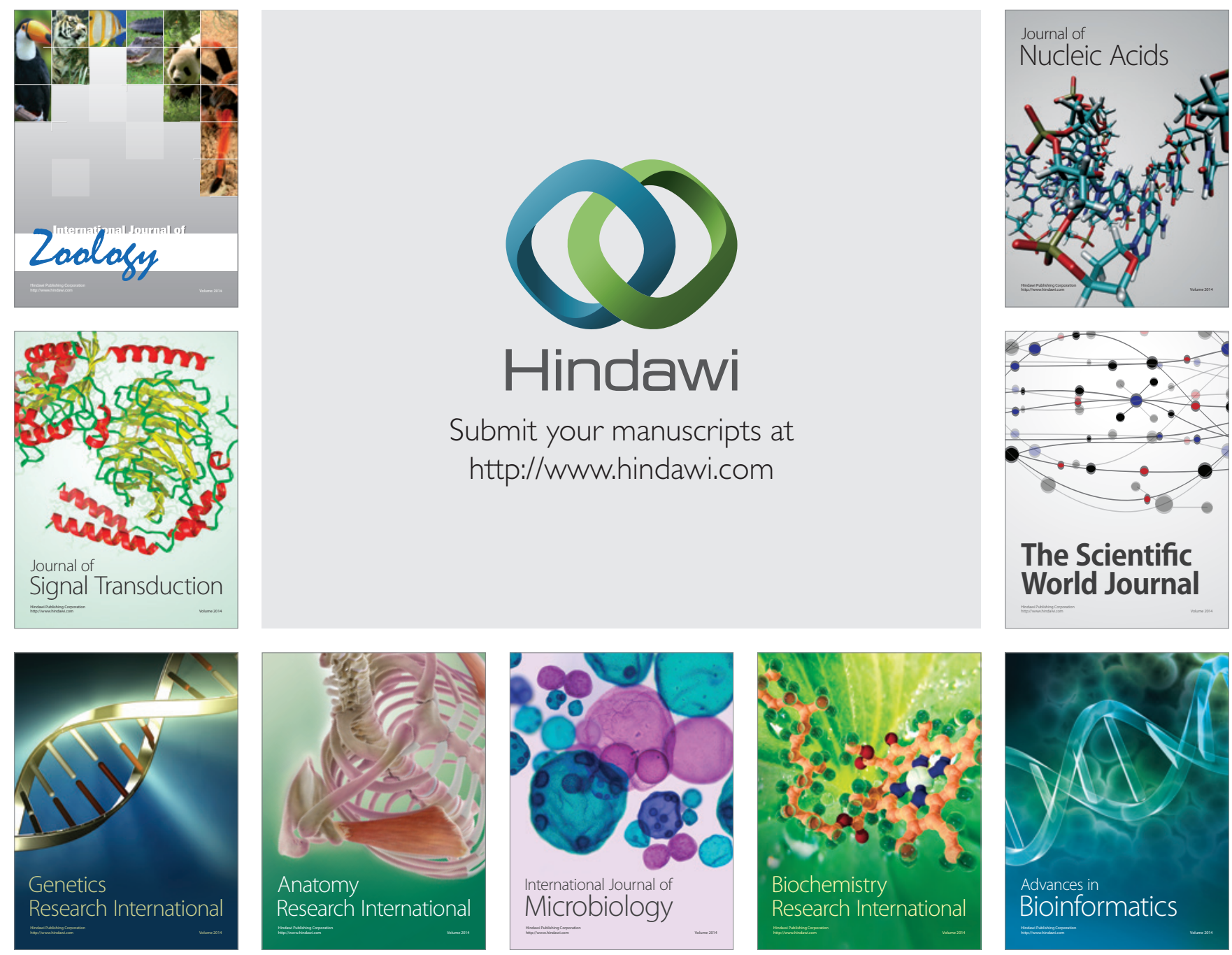

The Scientific World Journal
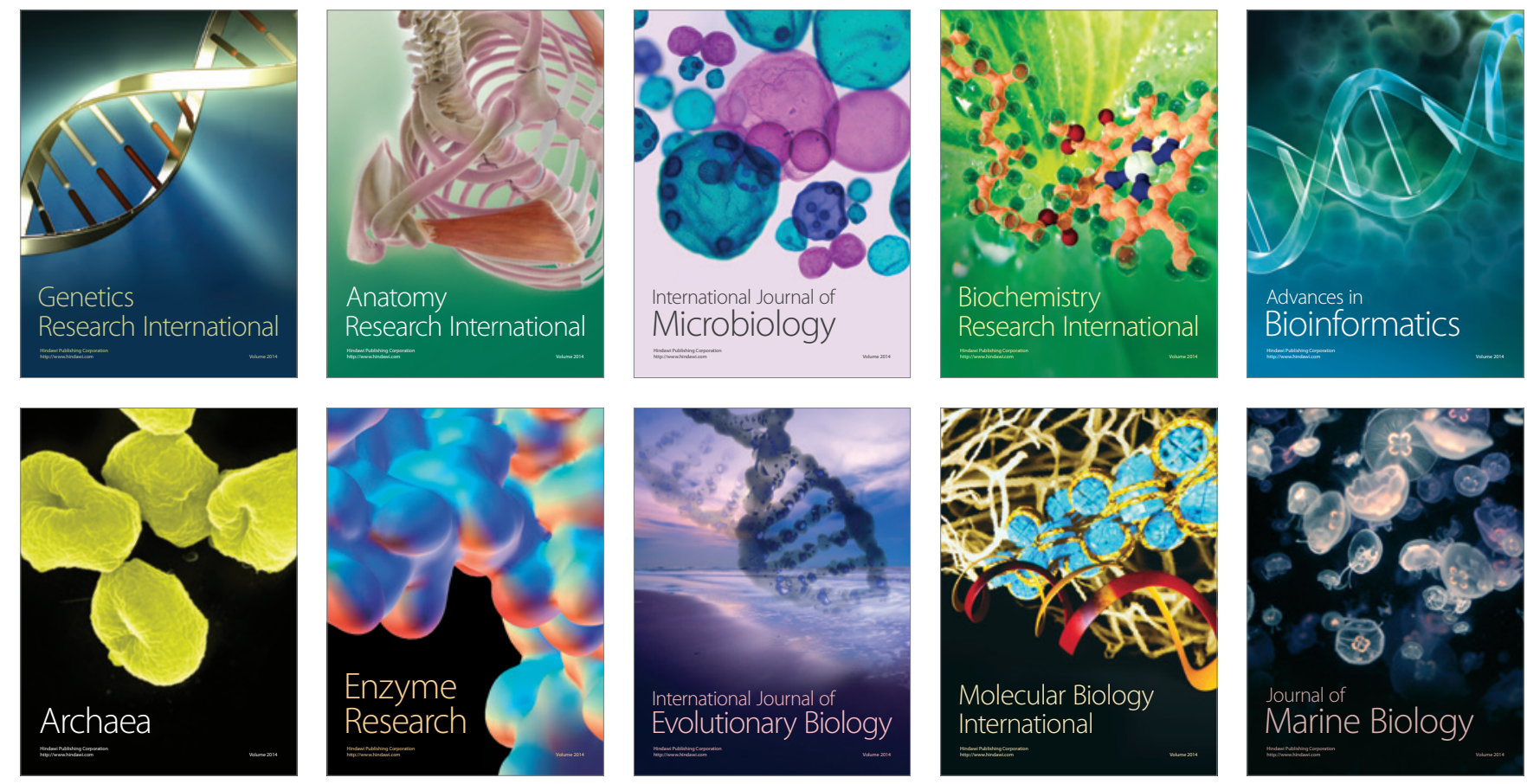